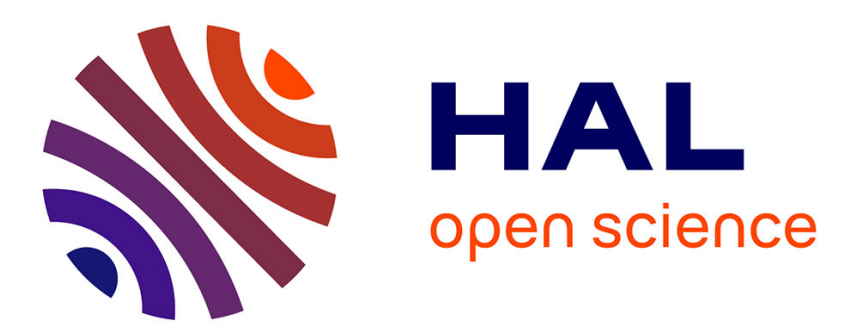

\title{
1,10-Bis(diphenylamino)-4,6-decadiyne as an active component of a radiochromic film dosimeter
}

Yasser S Soliman, Atef A Abdel-Fattah, Sylvain G Dutremez

\section{To cite this version:}

Yasser S Soliman, Atef A Abdel-Fattah, Sylvain G Dutremez. 1,10-Bis(diphenylamino)-4,6-decadiyne as an active component of a radiochromic film dosimeter. Radiation Physics and Chemistry, 2021, 189, pp.109714. 10.1016/j.radphyschem.2021.109714 . hal-03330391

\section{HAL Id: hal-03330391 \\ https://hal.science/hal-03330391}

Submitted on 31 Aug 2021

HAL is a multi-disciplinary open access archive for the deposit and dissemination of scientific research documents, whether they are published or not. The documents may come from teaching and research institutions in France or abroad, or from public or private research centers.
L'archive ouverte pluridisciplinaire HAL, est destinée au dépôt et à la diffusion de documents scientifiques de niveau recherche, publiés ou non, émanant des établissements d'enseignement et de recherche français ou étrangers, des laboratoires publics ou privés. 


\title{
1,10-Bis(diphenylamino)-4,6-decadiyne as an active component of a radiochromic film dosimeter
}

\author{
Yasser S. Soliman*a, Atef A. Abdel-Fattah ${ }^{\mathrm{a}}$, Sylvain G. Dutremez ${ }^{* b}$ \\ ${ }^{a}$ National Center for Radiation Research and Technology, Egyptian Atomic Energy Authority, \\ P.O. box 8029 Nasr City, Cairo 11787, Egypt \\ ${ }^{\mathrm{b}}$ ICGM, Université de Montpellier, CNRS, ENSCM, 34095 Montpellier Cedex 5, France
}

\begin{abstract}
Gamma-irradiation processes are very important tools for minimizing microbial load in dry food, inhibiting the proliferation of T-lymphocytes in blood, and for the sterilization of medical devices. To this end, a composite film dosimeter made of a radiation-sensitive monomer, 1,10-bis(diphenylamino)-4,6-decadiyne (DPD), embedded in poly(vinyl alcohol) was prepared using an automatic film applicator system. This polymeric film undergoes a color change from pale yellow to deep orange upon $\gamma$-irradiation due to topochemical polymerization of the DPD monomer. This color change is proportional to the amount of absorbed dose. With increasing absorbed doses, gradual disappearance of the $v_{\mathrm{C} \equiv \mathrm{C}}$ Raman band of the $\mathrm{C} \equiv \mathrm{C}-\mathrm{C} \equiv \mathrm{C}$ chemical groups is observed, and new $v_{\mathrm{C} \equiv \mathrm{C}}$ and $v_{\mathrm{C}=\mathrm{C}}$ bands ascribed to the formation of a polydiacetylene with an enyne structure are detected. The irradiated films exhibited two absorption maxima at 470 and $502 \mathrm{~nm}$ as measured by UV-Vis spectrophotometry, and the intensities of these bands increased with increasing absorbed doses. Analysis of these films using a high-resolution flatbed scanner (2400 dpi) showed an increase in optical density with increasing absorbed doses up to $269.1 \mathrm{kGy}$. Stability checks revealed that the irradiated films underwent an increase in the color intensity by $\approx 3.1 \%$ over 50 days of storage. In addition, relative humidities in the range $0-75.3 \%$ had a limited impact on the dose response of the films, with a $4 \%$ change in this range. The uncertainty $(2 \sigma)$ on dose measurements using the scanner was $4.46 \%$, demonstrating the effectiveness of this film dosimeter for radiation monitoring up to $296.1 \mathrm{kGy}$.
\end{abstract}

Keywords: Radiochromic film dosimeter, Radiation sensor, Diacetylene, Topochemical polymerization, Polydiacetylene, Flatbed scanner

\author{
* Corresponding authors \\ E-mail: yasser_shabaan@hotmail.com \\ E-mail: sylvain.dutremez@umontpellier.fr
}




\section{Introduction}

Ionizing radiations such as $\gamma$-rays, accelerated electrons and X-rays are used to irradiate blood or blood components, sterilize healthcare products, minimize microbial load in food, and modify polymers (ISO/ASTM, 2013). It is essential to verify that the dose delivered in each of these applications matches the prescribed dose within a specified limit. Absorbed doses used in such processes span a wide range going from a few tens of grays to over $100 \mathrm{kGy}$ (ISO/ASTM, 2013). Thus, manufacturing dosimeters in the form of films (Chu et al., 1990; Kawamura et al., 2020; Soliman et al., 2016) or gels (Baldock et al., 2010; Basfar et al., 2019; El Gohary et al., 2016; Koeva et al., 2008; Soliman et al., 2017; Sun et al., 2016) that can accurately measure absorbed doses is an important endeavor.

Radiochromic films based on the $\gamma$-initiated reduction of tetrazolium salts into formazans (Basfar et al., 2012, 2011; Emi-Reynolds et al., 2007; Kovács et al., 2000; Kozicki et al., 2018), taking advantage of the radiolytic cleavage of the $\mathrm{C}-\mathrm{H}$ bond in $\mathrm{Ar}_{3} \mathrm{C}-\mathrm{H}(\mathrm{Ar}=$ aryl $)$ compounds such as leucomalachite green and leuco crystal violet dyes (Alqathami et al., 2013; Mai et al., 2008; Soliman et al., 2014a; Soliman and Abdel-Fattah, 2013), or making use of the rupture of the $\mathrm{C}-\mathrm{CN}$ bond in $\mathrm{Ar}_{3} \mathrm{C}-\mathrm{CN}$ compounds such as pararosaniline cyanide, new fuchsine cyanide, and hexa(hydroxyethyl)pararosaniline cyanide dyes (Beshir et al., 2001; McLaughlin et al., 1985; Miller et al., 2000, 1988; Miller and Mclaughlin, 1980) have been explored for dosimetry purposes in various radiation technologies. In addition, radiation-sensitive compounds such as diacetylenes (DAs) are key materials for developing film dosimeters/sensors useful in a wide range of irradiation applications (Abdel-Fattah and Soliman, 2017; Chu et al., 1990; Devic, 2011; Mclaughlin et al., 1996; Patel, 1981; Soliman et al., 2013a; Soliman et al., 2018; Watanabe et al., 2006). In favorable cases, DAs polymerize topochemically in the crystalline state and undergo a color change when exposed to an ionizing radiation, thereby producing $\pi$ conjugated 1D structures, the polydiacetylenes (PDAs) (Scheme 1) (Baughman, 1972; Isa et al., 2017; Krishnan et al., 2019; Matsuzawa et al., 2001; Ogawa, 1995; Sarkar et al., 1999; Wegner, 1972, 1971; Weston et al., 2020). Gafchromic films are constructed from microcrystals of a DA dispersed in gelatin and coated onto polyester sheets (Chu et al., 1990; William L. McLaughlin et al., 1996; Saylor et al., 1988; Watanabe et al., 2006). These films are currently considered to be the most versatile dosimeters, as they cover wide dose ranges for irradiation applications (Butson et al., 2011; Chu et al., 1990; Devic, 2011; Patel, 1981; Vandana et al., 2011; Watanabe et al., 2006).
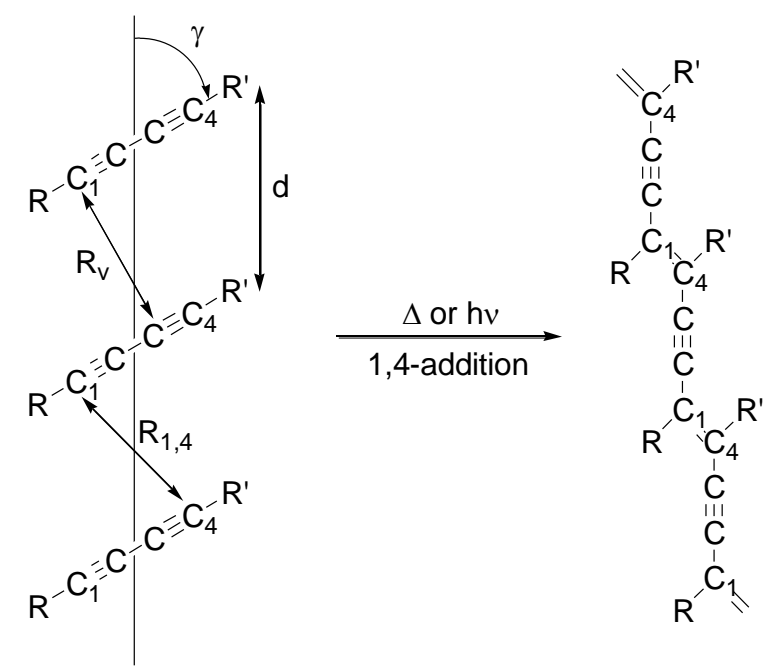
Scheme 1: Schematic representation of the topochemical principle of diacetylene polymerization: $4.7 \leq d \leq 5.2$ $\AA, 3.4 \leq \mathrm{R}_{\mathrm{v}} \leq 4 \AA, \mathrm{R}_{1,4} \leq 5 \AA, \gamma \approx 45^{\circ}$.

The behavior of Gafchromic MD-55 and DM-1260 films upon exposure to doses of 50 Gy has been investigated by monitoring the absorption band at $675 \mathrm{~nm}$ (William L. McLaughlin et al., 1996). These films take various shades of blue depending on the amount of absorbed radiation and the progression of the topochemical polymerization reaction. Interestingly, a blue shift of the absorption maximum from 675 to $660 \mathrm{~nm}$ was observed with increasing radiation dose. This was attributed to crystalline strain rearrangements of adjacent polymer arrays (William L. McLaughlin et al., 1996). Gafchromic MD-55 films are regarded as accurate dosimeters, capable of measuring doses with an uncertainty of less than 1\% near 6 Gy (Klassen et al., 1997). Gafchromic EBT3 films are very sensitive to radiation and can be used in the range of 0.5 to 100 Gy (Vaiano et al., 2019). These latter films were made of microcrystals of the lithium salt of 10,12-pentacosadiynoic acid (PCDA) dispersed in gelatin (Balakrishnan et al., 2010; Callens et al., 2016). This diacetylene is colorless and polymerizes upon exposure to ionizing radiation, forming blue-colored linear chains of poly-LiPCDA that possess extensive $\pi$-electron delocalization (Callens et al., 2016; Eckhardt et al., 1986). A flatbed scanner is usually used as a film scanning system in red-green-blue (RGB) color space (Van Battum et al., 2008). The maximum wavelength $\left(\lambda_{\max }\right)$ of EBT3 films after exposure to X-ray doses up to 9.52 Gy is $635.6 \pm 0.7 \mathrm{~nm}$ (Rink et al., 2005a).

A thin radiochromic film based on the PCDA monomer incorporated into polymeric films was developed for blood irradiation and food irradiation (Abdel-Fattah et al., 2012; Abdel-Fattah and Soliman, 2017). The PCDA polymeric film has a dose range of 5-4000 Gy depending on the selected wavelength and the concentrations of PCDA in the film (Abdel-Fattah and Soliman, 2017). This film turns blue upon exposure to $\gamma$-rays, showing two absorption bands at $670 \mathrm{~nm}$ and $620 \mathrm{~nm}$. However, the positions of these bands shift 2-4 nm towards shorter wavelengths (blue shift) depending on the absorbed dose. This observation is consistent with results obtained with MD-55 films that contain the PCDA monomer as an active ingredient (Balakrishnan et al., 2010; Klassen et al., 1997; Mclaughlin and Desrosiers, 1995). A blue shift in $\lambda_{\max }(675 \mathrm{~nm})$ of MD-55 films was noticed following an augmentation of the exposure dose (Mclaughlin and Desrosiers, 1995). However, there was no considerable shift in $\lambda_{\max }$ for EBT3 films $(635.6 \mathrm{~nm})$ up to an absorbed dose of $9.52 \mathrm{~Gy}$ (Rink et al., 2005a). One reason to explain a shift in $\lambda_{\max }$ is that the lengths of the polymer chains are changing with increasing absorbed dose (Rink et al., 2005b). Yet, it has also been put forth that such a shift may be indicative of conformational changes of the polymer chains as a result of structural changes in the crystal. For MD-55, a change in crystal structure is observed with increased dose due to the fact that the polymer chains are shorter than the equivalent number of monomer units (Rink et al., 2005b). This contraction increases the separation between the last polymer unit and the next available monomer molecule and, therefore, decreases the rate of polymerization with dose exposure (Rink et al., 2005a, 2005b). Such a phenomenon does not exist with EBT3 (Rink et al., 2005a, 2005b). In this case, the internal packing of the monomer molecules is stable and does not change with polymerization (Rink et al., 2005a). As a result, no significant decrease in the rate of polymerization is observed with increasing dose exposure (Rink et al., 2005a). 
Subsequently, films made of 2,4-hexadiyn-1,6-diol bis(n-butyl urethane) (HDDBU) dispersed in poly(vinyl alcohol) (PVA) were studied for potential use as a dosimeter up to $4 \mathrm{kGy}$. The UV-Vis spectrum of an irradiated film shows two absorption bands at $560 \mathrm{~nm}$ and $610 \mathrm{~nm}$, characteristic of a blue-violet coloration. A slight blue shift of these bands was observed with an increase in absorbed dose. Irradiation of a HDDBU-PVA film under oxygen reduces the film response by 16-23\%, thereby demonstrating the slow-down of the light-induced polymerization process by oxygen. Nevertheless, the response was negligibly affected by relative humidity (RH) during irradiation: a 2\% change was observed upon increasing the RH from 0 to $94 \%$ (Soliman et al., 2014b). In addition, a radiation-sensitive film of poly(hexa-2,4-diynylene adipate) (PHDA) in PVB was investigated for dose estimation in the range of 0.5 to $60 \mathrm{kGy}$ (Soliman et al., 2018a). This range is valuable for food irradiation and medical equipment sterilization. PHDA-PVB films exhibit a color change from very pale yellow to deep orange with an increase in the absorbed dose. The irradiated film shows one absorption band at $500 \mathrm{~nm}$ with a shoulder at $465 \mathrm{~nm}$. These bands shift slightly to longer wavelengths with an augmentation of absorbed dose. This film is practically insensitive to $\mathrm{RH}$ variation ranging from 0 to $54 \%$ during irradiation. However, the color of an irradiated film intensifies over time at room temperature (RT), in the dark or under laboratory light, indicative of ongoing polymerization after $\gamma$-ray exposure has ended (Soliman et al., 2018a).

Previously, a DA monomer chemically different from the aforementioned ones, 1,10-bis(diphenylamino)-4,6decadiyne (DPD), was investigated (Scheme 2) (Deschamps et al., 2010). This diacetylene exhibits solid-state polymerization reactivity upon exposure to a ${ }^{137} \mathrm{Cs} \gamma$-ray source (Al Choueiry et al., 2010; Deschamps et al., 2010). The UV-Vis spectrum of poly-DPD shows an absorption band at $\sim 470 \mathrm{~nm}$ in chloroform solution and at $\sim 517 \mathrm{~nm}$ in the solid state at $13 \mathrm{~K}$ (Al Choueiry et al., 2010; Deschamps et al., 2010). Upon exposure to low doses of $\gamma$-rays, colorless crystals of DPD turned pale yellow, then became deep orange or red at higher doses (Deschamps et al., 2010). To the best of our knowledge, DPD has never been tested in radiation dose measurements, and its detailed response to $\gamma$-irradiation is unknown. Consequently, we sought to investigate the response of this monomer to ionizing radiation, while evaluating its potential use for dose monitoring. A radiochromic film dosimeter was prepared by incorporation of DPD into a PVA matrix. Then, this film was studied in the dose range of 0 to $269.1 \mathrm{kGy}$ using a spectrophotometer, a high-resolution flatbed scanner, and a Raman spectrometer. In addition, the doses measured by the DPD-PVA film were compared with the doses measured by the radiochromic dosimeter film of FWT-60 irradiated at an industrial radiation facility for radiation processing. Furthermore, the influence of RH on the response of DPD-PVA films during irradiation, the postirradiation stability of the film response under different storage conditions, and the uncertainty of dose measurement were discussed. Last, the theoretical energy response dependency based on calculations of the mass energy-absorption coefficient $\left(\mu_{\mathrm{en}} / \rho\right)_{\text {film }}$ of the DPD-PVA films was evaluated and compared with that of soft tissue and alanine standard dosimeter. 


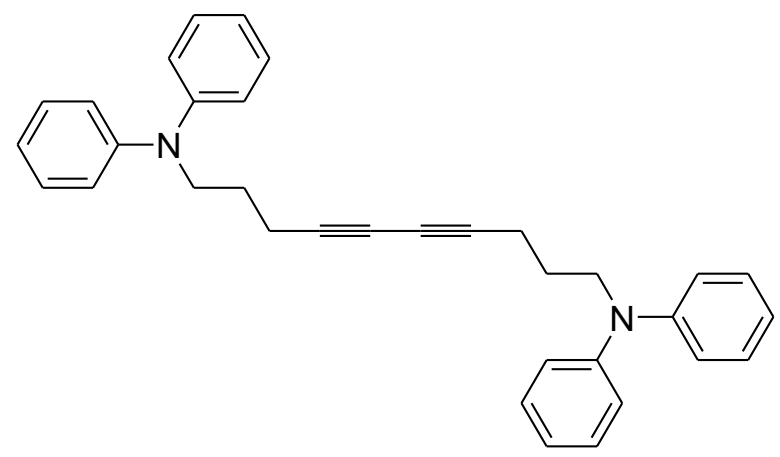

Scheme 2: Chemical structure of DPD.

\section{Materials and methods}

\subsection{Preparation of DPD-PVA films}

The radiochromic film of DPD-PVA was prepared by successively mixing three separate solutions (A, B, and C). Solution A was prepared by dissolving $0.4 \mathrm{~g}$ of PVA (Acrōs Organics, average molecular weight $88 \times 10^{3}$ ) in a $12 \mathrm{~mL}$ aliquot of double distilled water, at $75^{\circ} \mathrm{C} \pm 3^{\circ} \mathrm{C}$, under magnetic stirring. This solution was left to cool to RT prior to use. Then, a $0.0025 \mathrm{~g}$ portion of sodium dodecyl sulfate (SDS) (Sigma-Aldrich) and a $0.015 \mathrm{~g}$ portion of Tween ${ }^{\circledR} 80$ (Sigma-Aldrich) were added to solution A. Solution B was prepared by dissolving $0.2 \mathrm{~g}$ of DPD monomer in about $1.5 \mathrm{~mL}$ of tetrahydrofuran (THF) (Sigma-Aldrich). DPD was synthesized following a reported protocol (Deschamps et al., 2010). Solution C consisted of a viscous solution of PVA in water (1.0 g of PVA in $8 \mathrm{~mL}$ of double distilled water) prepared at $75^{\circ} \mathrm{C} \pm 3^{\circ} \mathrm{C}$, under magnetic stirring. Solution $\mathrm{B}$ was poured into solution $\mathrm{A}$ in a dropwise manner using a syringe, with concomitant homogenization of solution A at 10,000 $\mathrm{rpm}$. This resulted in the formation of an emulsion. Then, the DPD-PVA emulsion was poured into solution $\mathrm{C}$ over a period of ten minutes, during which time vigorous magnetic stirring was maintained. The resulting mixture was kept under stirring for another ten minutes to evaporate the THF from the aqueous solution. The final concentration of DPD monomer in the PVA matrix was $14.3 \mathrm{phr}$ (parts per hundred parts of resin). Finally, the mixture was coated as a $400 \mu \mathrm{m}$ thick film onto a polyester sheet (A4 size), at RT, using an automatic film applicator system (Braive Instrument, Belgium). The coated film was allowed to dry in the dark, at RT, for about 72 hours, then it was stripped from the polyester sheet. To reduce edge effects, the $2 \mathrm{~cm}$-wide borders of the prepared films were cut out. Subsequently, the stripped film was cut into $1 \times 1 \mathrm{~cm}^{2}$ pieces for spectrophotometric measurements and $2 \times 2 \mathrm{~cm}^{2}$ slabs for scanner analyses. The thickness of the fabricated film was $36 \pm 3 \mu \mathrm{m}(1 \sigma)$.

\subsection{Irradiation experiments}

To study DPD-PVA films and establish their dose-response function, different samples were irradiated at various absorbed doses (0-269.1 kGy) using $\gamma$-rays from the ${ }^{60}$ Co research facility (Gamma Cell 220 Excel manufactured by MDS Nordion, Canada). This facility includes annular sources, a cylindrical drawer to hold the samples, and a mechanism that moves the cylindrical drawer up or down to the ${ }^{60} \mathrm{Co}$ source. A specially designed poly(methyl methacrylate) (PMMA) holder was used to obtain an electronic equilibrium during irradiation and to irradiate the films at the center of the cylindrical drawer. The dose rate of the facility at the center during this study was about 
$0.92 \mathrm{kGy} \mathrm{h}^{-1}$. The National Physical Laboratory (NPL) in UK used standard alanine pellets to calibrate the dose rate of this facility. Three sets of alanine pellets were used for this calibration ( 3 pellets at each dose set). The overall uncertainty reported by NPL in dose rate calibration was $2.2 \%$ at $2 \sigma$.

In order to evaluate DPD-PVA films in industrial radiation processing conditions, ten DPD-PVA film pieces were irradiated simultaneously with radiochromic films of FWT-60 (produced by Far West Technology Incorporation, USA) at the industrial ${ }^{60}$ Co facility (Egypt Mega Gamma I irradiator, designed and installed by MDS Nordion). Calibration of this facility was discussed previously (Sephton et al., 2007; Soliman et al., 2013b). FWT-60 films $\left(10 \times 10 \times 0.05 \mathrm{~mm}^{3}\right)$ are useful for doses ranging from 0.5 to $200 \mathrm{kGy}$ (Far West Technology Inc., 2020). Irradiation of both types of films was achieved at a nominal dose of $25 \mathrm{kGy}$ in the industrial facility. The FWT-60 films were calibrated at the research facility (traceable to NPL) in nearly the same conditions of use as those of the industrial irradiation facility, as previously defined (Soliman et al., 2013b). Determination of the doses absorbed by the FWT-60 and DPD-PVA films was carried out with a spectrophotometer and a flatbed scanner, respectively.

\subsection{Spectroscopic characterization}

The optical absorption spectra of irradiated and unirradiated DPD-PVA films were recorded using a UV-Vis Evolution 500 spectrophotometer (Thermo Electron Corp., UK) in the wavelength range 400-600 nm. The dosimeter response was expressed in terms of the relative absorbance $\left(\mathrm{A}_{\mathrm{i}} / \mathrm{A}_{\mathrm{o}}\right)$ at $502 \mathrm{~nm}$ and $507 \mathrm{~nm}$, where $\mathrm{A}_{\mathrm{i}}$ and $A_{o}$ are the absorbance of irradiated and unirradiated films, respectively. FWT-60 films were analyzed and calibrated at $600 \mathrm{~nm}$ using the same spectrophotometer (Far West Technology Inc., 2020; Soliman et al., 2013b) to calculate absorbed doses given by the industrial facility and compare with the doses measured by the DPDPVA films.

Raman spectra at RT were obtained using a Renishaw InVia Raman microscope. The objective of the microscope was $\times 50$ and the excitation wavelength $\left(\lambda_{\mathrm{ex}}\right)$ was $785 \mathrm{~nm}$. The laser power on sample was 510 or $1900 \mu \mathrm{W}$ and the acquisition time was $50 \mathrm{~s}$.

\subsection{Scanning films with a high-resolution flatbed scanner}

The DPD-PVA films were analyzed using a high-resolution flatbed scanner (Epson Perfection V850 Pro, made in Indonesia by Seiko Epson Corporation) equipped with a dual lens system. This scanner can operate in both transmission and reflection modes. The detailed protocol for analysis of radiochromic films using flatbed scanners was described recently in the literature (Devic, 2011; Devic et al., 2005, 2004; Miller et al., 2000; Paelinck et al., 2007; Van Battum et al., 2008). Herein, the unirradiated and irradiated films were scanned using the reflection mode. The color was analyzed with a $2400 \mathrm{dpi}(\sim 0.0106 \mathrm{~mm} / \mathrm{pixel})$ nominal resolution using threecolor channels (red, green, blue) with a 48-bit color depth. Thereafter, the scanned images were saved in the TIFF format. Four films were irradiated at each dose point in the 0 to $269.1 \mathrm{kGy}$ range and analyzed by the scanner.

Before scanning the radiochromic films, the scanner was allowed to warm up for 30 min (Lynch et al., 2006; Williams and Metcalfe, 2011). Then, a region of interest $(2 \mathrm{~cm} \times 2 \mathrm{~cm})$ in the scanner was chosen and scanned ten times without the samples. The unirradiated films were scanned at the predetermined region and were then subjected to irradiation. After irradiation, the films were scanned under the same conditions. TIFF images for 
each dosimeter film were next acquired in RGB color space. The acquired images were analyzed using the ImageJ software (Schneider et al., 2012). The RGB images were analyzed at the central regions $\left(1.2 \times 1.2 \mathrm{~cm}^{2}\right)$ of the films at three channels (red, green, and blue). By doing so, any influence from the edges of the films is greatly diminished. Thereafter, the mean pixel values $(\mathrm{PV})$ for each region of interest without sample, $\mathrm{PV}_{\mathrm{o}}$, with unirradiated film, $\mathrm{PV}_{\text {uni }}$, and with irradiated film, $\mathrm{PV}_{\text {irr }}$, were obtained. The optical densities (OD) for unirradiated films $\left(\mathrm{OD}_{\text {uni }}\right)$ and for irradiated films $\left(\mathrm{OD}_{\text {irr }}\right)$ were determined using Eqs. (1) and (2) (Ferreira et al., 2009).

$$
\mathrm{OD}_{\mathrm{uni}}=-\log \frac{\mathrm{PV}_{\mathrm{uni}}}{\mathrm{PV}_{\mathrm{o}}}
$$

$$
\mathrm{OD}_{\text {irr }}=-\log \frac{\mathrm{PV}_{\text {irr }}}{\mathrm{PV}_{\mathrm{o}}}
$$

Then, the response of the DPD-PVA films was calculated as shown in Eq. (3):

$$
\text { Response }=\text { Relative } \mathrm{OD}=\frac{\mathrm{OD}_{\text {irr }}}{\mathrm{OD}_{\mathrm{uni}}}
$$

The relative OD represents the response of the film to $\gamma$-rays. The response value for each film and the mean values of the four irradiated films were recorded at each dose set. Then, the average response was plotted against the absorbed dose to establish the dose response curve (dose response function) up to $269.1 \mathrm{kGy}$.

\subsection{Effect of relative humidity on dosimeter response}

RH can influence the dosimeter response during irradiation. Thus, the influence of humidity on the performance of DPD-PVA films was assessed by exposing these films to $\gamma$-rays under various RH conditions ranging from 0 to $75.3 \%$. Experiments under controlled humidity conditions were carried out by hanging unirradiated films (four films at each RH value) in tightly closed tubes over saturated salt solutions of $\mathrm{KOH}(\sim 8.2 \%), \mathrm{MgCl}_{2}(\sim 33 \%)$, $\mathrm{Mg}\left(\mathrm{NO}_{3}\right)_{2}$ ( $\left.\sim 53 \%\right)$, and $\mathrm{NaCl}$ ( 75.3\%) (Greenspan, 1977; Wexler and Hasegawa, 1954). For 0\% $\mathrm{RH}$, dehydrated silica gel was utilized instead of saturated salt solutions. All of the suspended films were kept in the sealed tubes for $\sim 72 \mathrm{~h}$ at RT in order to equilibrate the water contents in the films before irradiation. Thereafter, the sealed tubes were irradiated simultaneously at $30 \mathrm{kGy}$. The irradiated films were analyzed with the scanner, and the scanned images were decrypted with the ImageJ program using the blue channel.

\subsection{Post-irradiation stability}

Two groups of DPD-PVA films were irradiated at $30 \mathrm{kGy}$. Then, these films were analyzed using the flatbed scanner (Epson Perfection V850 Pro) at different time intervals over a period of 50 days after irradiation. During these analyses, the first group was stored in the dark, at RT, and the second group was stored under standard laboratory light (fluorescent light plus normal daylight).

\subsection{Theoretical energy dependence}

To study the effect of photon energy on the dosimeter response, theoretical calculations were carried out using the NIST physical database (Hubbell et al., 1995; Seltzer, 1993) to obtain the mass energy-absorption coefficients $\left(\mu_{\mathrm{en}} / \rho\right)_{\text {film }}$ of the DPD-PVA film dosimeter. The $\left(\mu_{\mathrm{en}} / \rho\right)_{\text {media }}$ values for the films, $\left(\mu_{\mathrm{en}} / \rho\right)_{\text {film }}$, the soft tissue, $\left(\mu_{\mathrm{en}} / \rho\right)_{\mathrm{st}}$, and for alanine, $\left(\mu_{\mathrm{en}} / \rho\right)_{\text {alanine }}$, were calculated relative to the $\left(\mu_{\mathrm{en}} / \rho\right)_{\text {water }}$ coefficients of water. 
Photon energies were in the range $0.01-20 \mathrm{MeV}$. The $\left(\mu_{\mathrm{en}} / \rho\right)_{\text {film }}$ values of the DPD-PVA film dosimeter were calculated by multiplying the $\mu_{\mathrm{en}} / \rho$ value of each element in the film by its mass fraction and then summing all of the individual values.

\section{Results and discussion}

\subsection{Color change and spectrophotometric assessment of DPD-PVA films}

The color of DPD-PVA films visibly changed from very pale yellow (nearly colorless), to orange-yellow, and then to deep orange when the samples were exposed to increasing amounts of $\gamma$-rays (Table 1). The observed color intensifies proportionally with increasing absorbed dose. This is due to topochemical polymerization of the DPD monomer in the PVA film by means of $\gamma$-rays.

Table 1: Variation of the color intensity of DPD-PVA film pieces with absorbed dose.

\begin{tabular}{|c|c|}
\hline Dose, kGy & Color of films \\
\hline 0.0 & \\
\hline 5.0 & \\
\hline 10.0 & \\
\hline 20.0 & \\
\hline 30.0 & \\
\hline 50.0 & \\
\hline 100.0 & \\
\hline 159.1 & \\
\hline 229.1 & \\
\hline
\end{tabular}




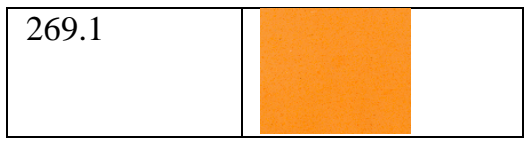

Fig. 1 shows the absorption spectra $(400-600 \mathrm{~nm})$ of several radiochromic film samples exposed to various $\gamma$-ray doses. Upon irradiation, two maxima $\left(\lambda_{\max }\right)$ at $470 \mathrm{~nm}$ and $502 \mathrm{~nm}$ appeared, and these maxima shifted towards higher wavelengths (red shift) as the absorbed dose increased. The intensities of these absorption bands increase with further irradiation. Yet, the change in absorbance with increasing $\gamma$-ray dose is small (i.e. the radiation dose sensitivity is low) (Fig. 1). The band at $470 \mathrm{~nm}$ is reminiscent of the yellow state of poly-DPD, as observed previously in chloroform solution (Deschamps et al., 2010). The $502 \mathrm{~nm}$ band resembles the $517 \mathrm{~nm}$ band observed in the solid state at $13 \mathrm{~K}$ (Al Choueiry et al., 2010; Deschamps et al., 2010), suggesting that a red phase PDA was also present. Therefore, two forms of poly-DPD seem to co-exist in the PVA film, a yellow phase and a red phase. Interestingly, the change in absorbance for the band at $502 \mathrm{~nm}$ is much more perceptible than that of the band at $470 \mathrm{~nm}$ upon increasing the $\gamma$-ray dose: for instance, for a $30 \mathrm{kGy}$ dose, the absorbance of the $502 \mathrm{~nm}$ band is 2.56 times higher than the absorbance of the $470 \mathrm{~nm}$ band. In addition, a nearly $5 \mathrm{~nm}$ shift in $\lambda_{\max }$ at 90 kGy was observed for the band originally located at $502 \mathrm{~nm}$, i.e. $\lambda_{\max }=507 \mathrm{~nm}$. This phenomenon is a serious drawback when trying to quantify absorbed doses using this technique. Such a shift may be due to an increase in the length of the chains with increasing exposure to $\gamma$-rays and to a better $\pi$-electron delocalization along the polymer backbone. Consequently, the energy of the $\pi-\pi^{*}$ transition decreases with an increase in the degree of polymerization. An increase in the length of the chains moves the $\lambda_{\max }$ of the polymer to longer wavelengths (bathochromic shift) (Isa et al., 2017; Samuel et al., 1994). A shift in the absorption peaks to the visible region was also reported for PHDA-PVB films (Soliman et al., 2018a). The optical spectra of irradiated PHDA-PVB films exhibit an absorption peak at $500 \mathrm{~nm}$ with a shoulder at $465 \mathrm{~nm}$. These two bands shift to higher wavelengths (red shift) as the absorbed dose increases. However, in the case of PCDA-PVB films, the $\lambda_{\max }$ of poly-PCDA shifts to shorter wavelengths (blue shift) with an increase in absorbed dose of ionizing radiation (Abdel-Fattah and Soliman, 2017) or UV radiation (Isa et al., 2017).

Four $1 \times 1 \mathrm{~cm}^{2}$, randomly selected, radiochromic films were analyzed at 502 and $507 \mathrm{~nm}$ before and after irradiation. The response in terms of relative absorbance, $\mathrm{A}_{\mathrm{i}} / \mathrm{A}_{\mathrm{o}}$, was then calculated at the two wavelengths and an average value was determined. The dose response curve shown in Fig. 2 was obtained by plotting average values against absorbed doses, thereby limiting the problem of the shift in $\lambda_{\max }$ with increasing absorbed dose. As can be seen, the dosimeter response increases nonlinearly with increasing absorbed dose, then saturates at 90 $\mathrm{kGy}$. However, linearity of the response is observed up to $30 \mathrm{kGy}$. The reported radiation sensitivity (as expressed by the slope of the linear part in Fig. 2) is about $0.027 \mathrm{kGy}^{-1}$. For the analyses at 502 and $507 \mathrm{~nm}$ (Fig. 2), the radiation sensitivities are 0.028 and $0.025 \mathrm{kGy}^{-1}$, respectively. Owing to the low absorbance values of the irradiated films and the small changes with absorbed doses, the signal-to-noise ratio becomes quite poor and induces an error in absorbed dose measurements. In addition, the variability of the response between repeated measurements is higher, as indicated by the error bars in Fig 2. This was due to the shift in $\lambda_{\max }$. 


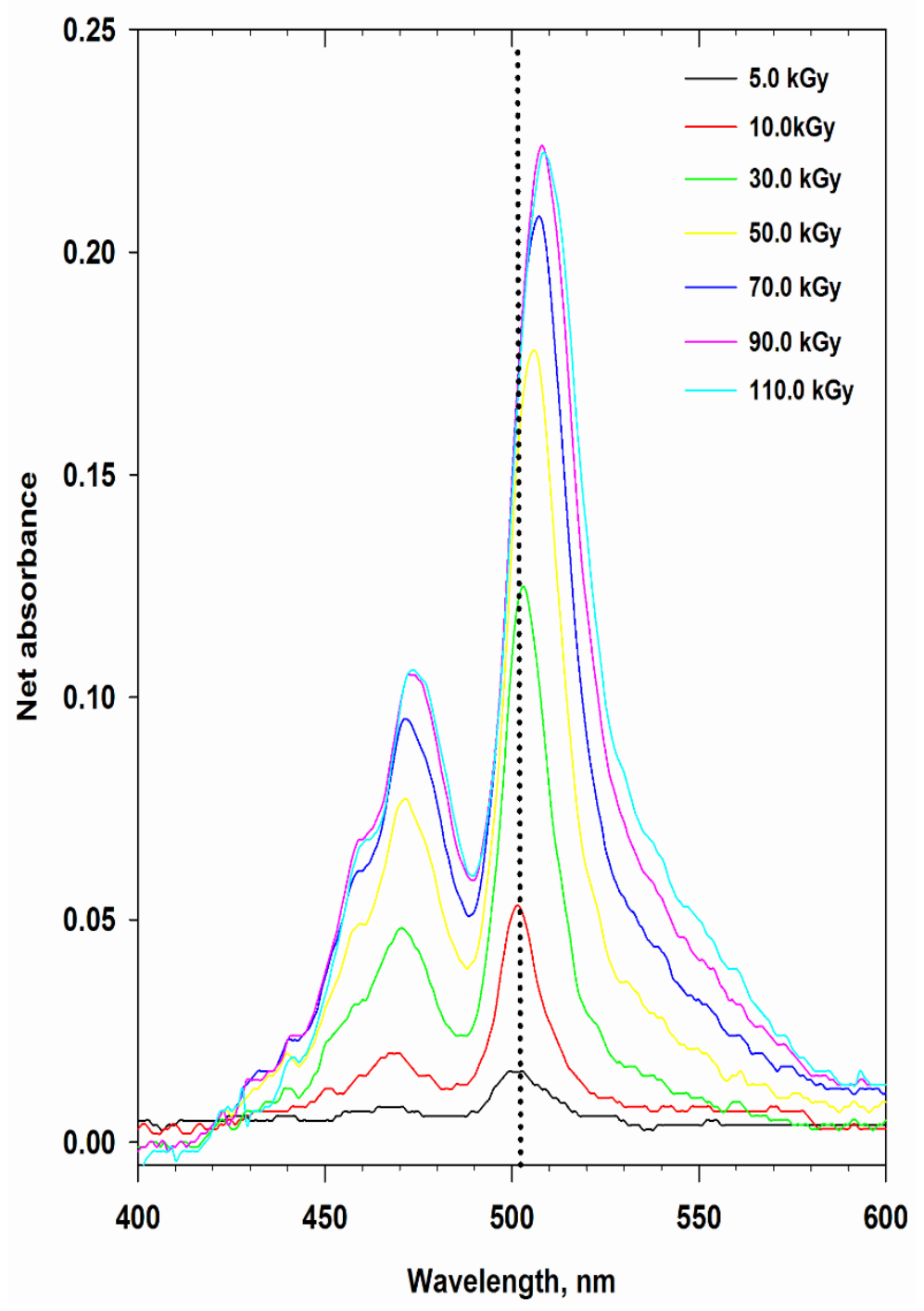

Fig. 1: Absorption spectra of DPD-PVA films exposed to various absorbed doses of $\gamma$-rays from the ${ }^{60} \mathrm{Co}$ research facility, as measured with a UV-Vis spectrophotometer. 


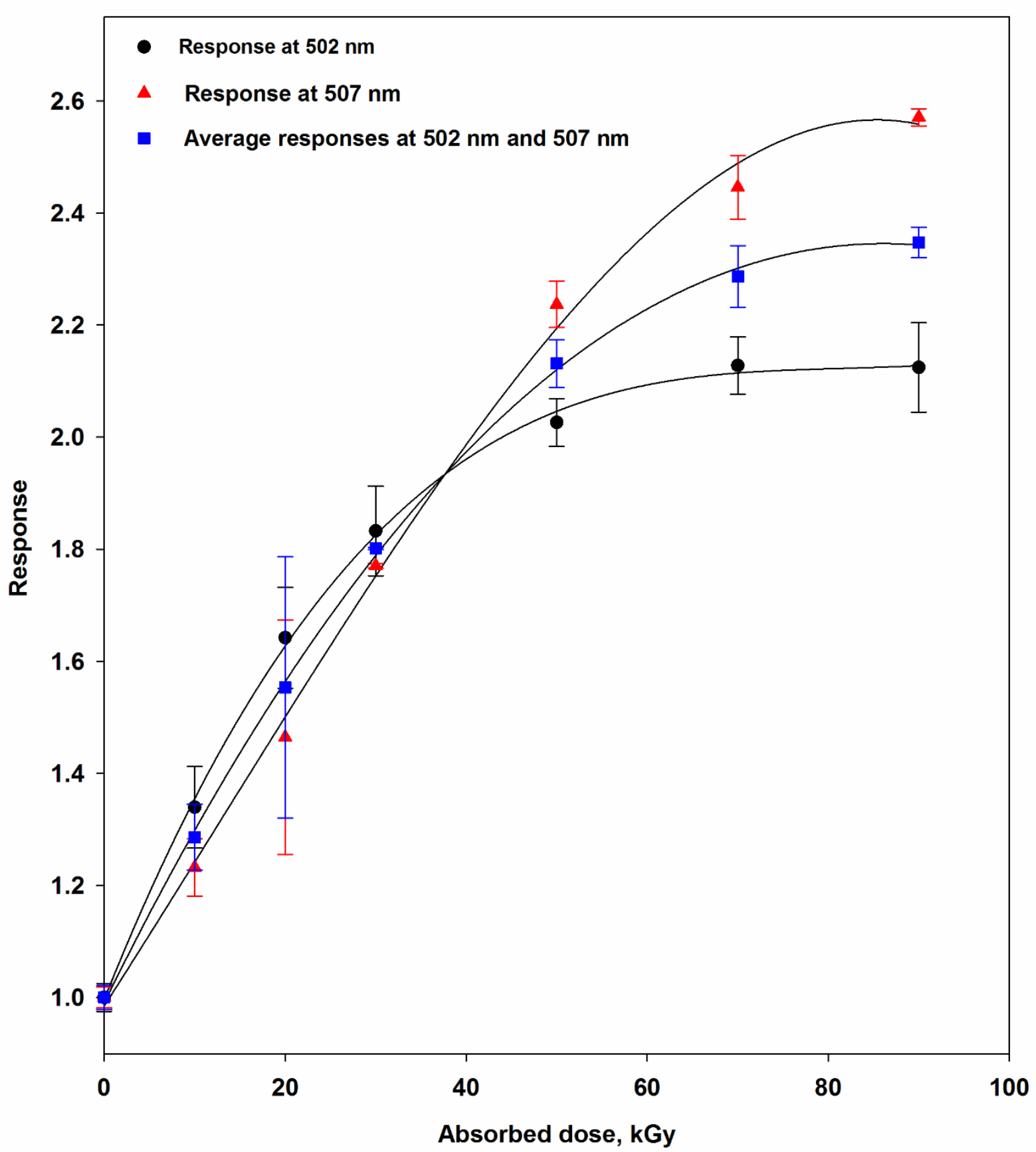

Fig. 2: Dose response curve of the radiochromic films irradiated in the dose range 0-90 kGy, as measured with a UV-Vis spectrophotometer. The responses at 502 and $507 \mathrm{~nm}$ are shown, along with the mean of these two responses. Error bars are the standard deviation of the mean value of the spectrophotometer response for the four films analyzed at each dose. 


\subsection{Epson V850 scanner analysis of DPD-PVA films}

A scanner was used to investigate the 2D measurement capabilities of the elaborated film dosimeters, as standard film dosimeters are often scanned with Epson or Vidar scanners. In fact, previous studies have shown that simple flatbed scanners could be used for scanning such radiochromic films (Ferreira et al., 2009; Miller et al., 2000; Paelinck et al., 2007). Fig. 3 shows the dose response curves of DPD-PVA films in the dose range 0-269.1 kGy. Four $2 \times 2 \mathrm{~cm}^{2}$ randomly selected films were used to establish the response curves. The response values were derived from images measured by the scanner and analyzed on three channels (red, green, and blue). The change in signal detected with the red channel is quite limited. Consequently, this channel is not suitable for dosimetry measurements. However, appreciable changes in response with absorbed doses was observed when the analysis was performed with the green and blue channels. For the blue and green channels, the response curves are fitted with a third degree polynomial $\left(r^{2}=0.999\right)$ and a second degree polynomial $\left(r^{2}=0.998\right)$, respectively. Furthermore, linearity of the response was noted in the low dose regions ( $0-30 \mathrm{kGy})$. The change in response with absorbed dose is more pronounced for the blue channel analysis than for the green channel analysis. The radiation sensitivity of the films, as determined from the slope of the linear part of the curves in Fig. 3, is about 2.21 times higher for the blue channel analysis than for the green channel analysis, with values of 0.075 and $0.023 \mathrm{kGy}^{-1}$, respectively. The radiation sensitivity of the films using the blue channel detection mode is 1.81 times higher than that obtained from spectrophotometer analysis at 502 and $507 \mathrm{~nm}$. In addition, the dose range extends to $269.1 \mathrm{kGy}$ in the case of the blue channel analysis, while it only goes to $90 \mathrm{kGy}$ for measurements with the spectrophotometer (Fig. 2). The flatbed scanner technique makes the present dosimeter sensitive to a wider range of doses compared to the spectrophotometer technique, which is valuable for certain types of irradiation applications. Thus, the blue channel readout was used to analyze this radiochromic film for dosimetry applications. 


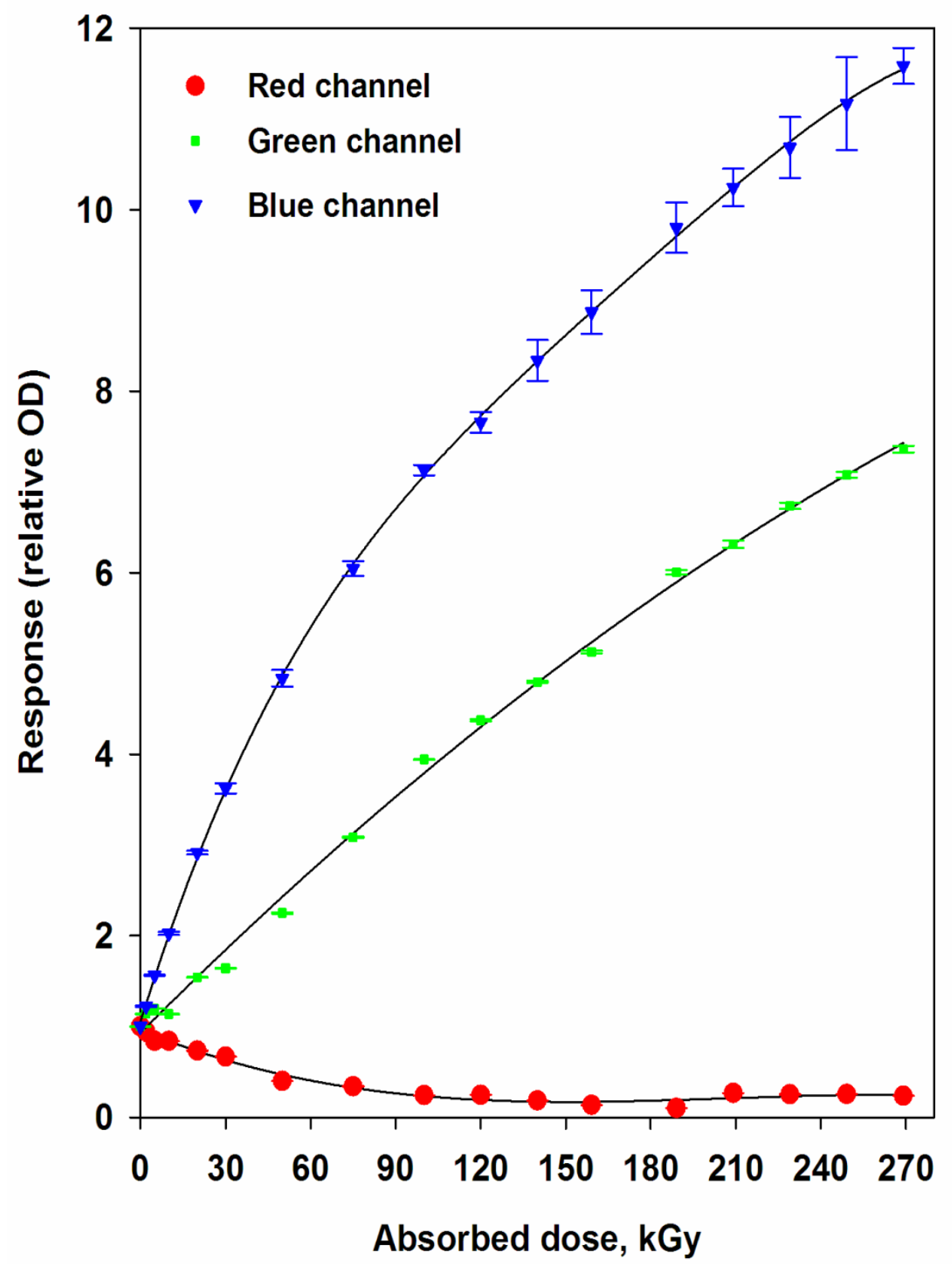

Fig. 3: Dose response curve of the radiochromic films irradiated in the 0-269.1 kGy dose range. Measurements were carried out with an Epson Perfection V850 Pro flatbed scanner, and images were analyzed with the ImageJ software at three channels (red, green, and blue). The color was analyzed with a $2400 \mathrm{dpi}(\sim 0.0106 \mathrm{~mm} / \mathrm{pixel})$ nominal resolution. The $1.2 \times 1.2 \mathrm{~cm}^{2}$ (i.e. $1133.9 \times 1133.9$ pixels) central regions of the $2 \times 2 \mathrm{~cm}^{2}$ DPD-PVA films were examined. Error bars correspond to the standard deviation of the mean value of the scanner response.

In order to use the present film for dose measurements in radiation processing, a calibration curve (reciprocal of the response curve shown in Fig. 2) of the blue channel analysis was established. This calibration plot is provided in Fig. 4a. The Table Curve 2D program (Version 5.01, Jandel Scientific Software) was used to fit the data and obtain the calibration function and the residual\% curve (Fig. 4b). Residuals\% are defined as $\left(\left(D_{\text {calculated }}-D_{\text {delivered }}\right) / \mathrm{D}_{\text {delivered }} \times 100\right)$ with $\mathrm{D}_{\text {calculated }}$ coming from the fitting function (Sharpe and Miller, 2009). The computed fitting function for this calibration curve is a third degree polynomial of the type: $y=a+b x+c x^{2}+d x^{3}$ 
where $\mathrm{y}$ is the absorbed dose in kGy and $\mathrm{x}$ is the dosimeter response value reported on the $\mathrm{x}$-axis of Fig. 4a. a, b, $\mathrm{c}$, and $\mathrm{d}$ are fitting constants; they are equal to $-6.0915,5.3408,1.0863$, and 0.0434 , respectively. The calculated correlation coefficient $\left(\mathrm{r}^{2}\right)$ and F-statistics value, as obtained from Table Curve, were 0.9998 and 20562.84 , respectively. The uncertainty of the selected function is $1.36 \%(\sigma)$. This value was obtained using Eq. (4) (Sharpe and Miller, 2009).

$$
u=\sqrt{\frac{\sum(\text { residuals } \%)^{2}}{n_{d}-n_{c}}}
$$

where $n_{d}$ is the number of film dosimeters and $n_{c}$ is the number of coefficients in the supposedly correct fitting function.

The closeness of $r^{2}$ to 1 , the greater the dispersion of the residual $\%$ in Fig. $\mathbf{4 b}$, the higher the F-statistics value and the lower the uncertainty in fitting the calibration curve validate the choice of the selected function in the dosimetry evaluation (ASTM International, 2015; Sharpe and Miller, 2009).

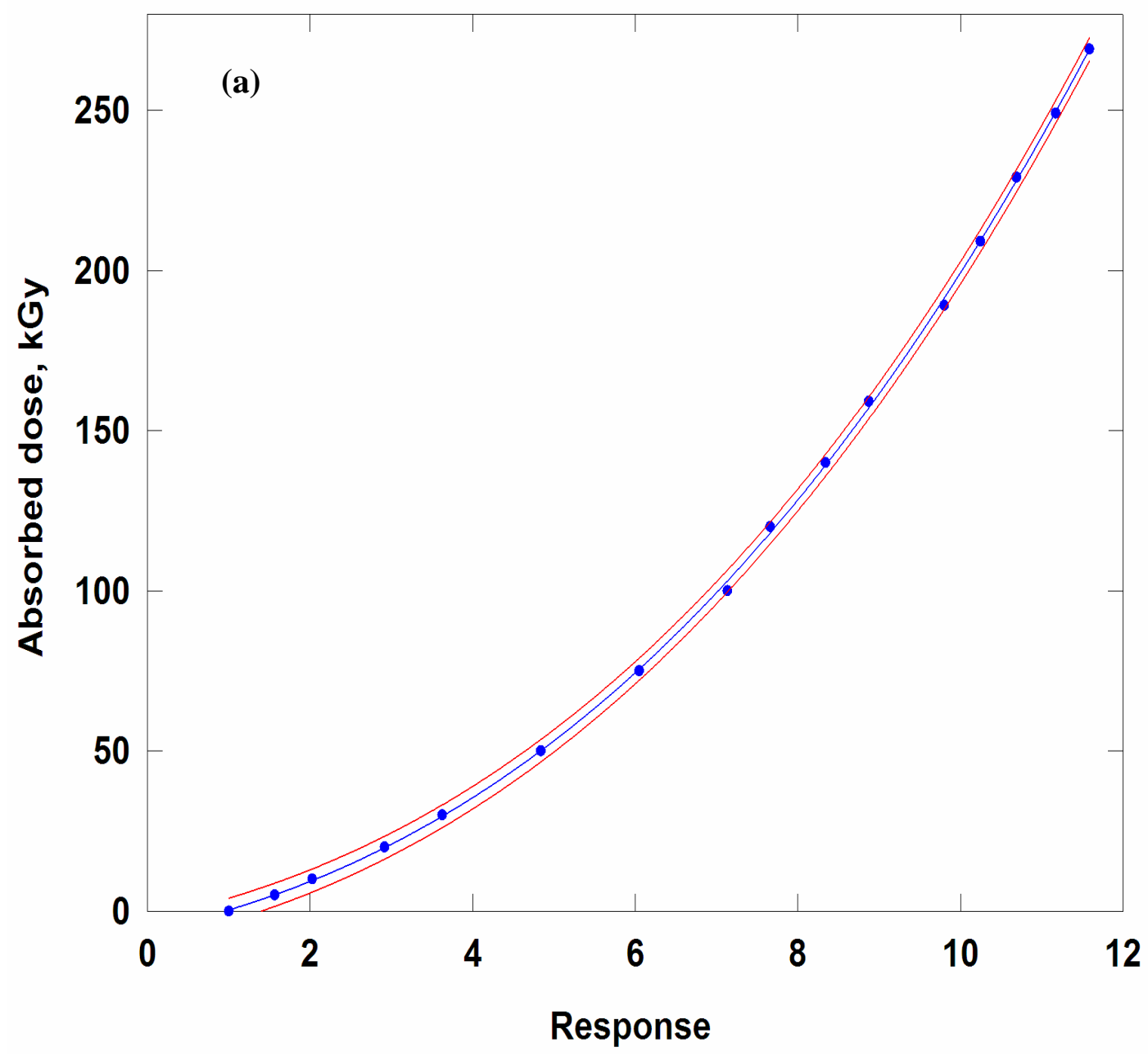




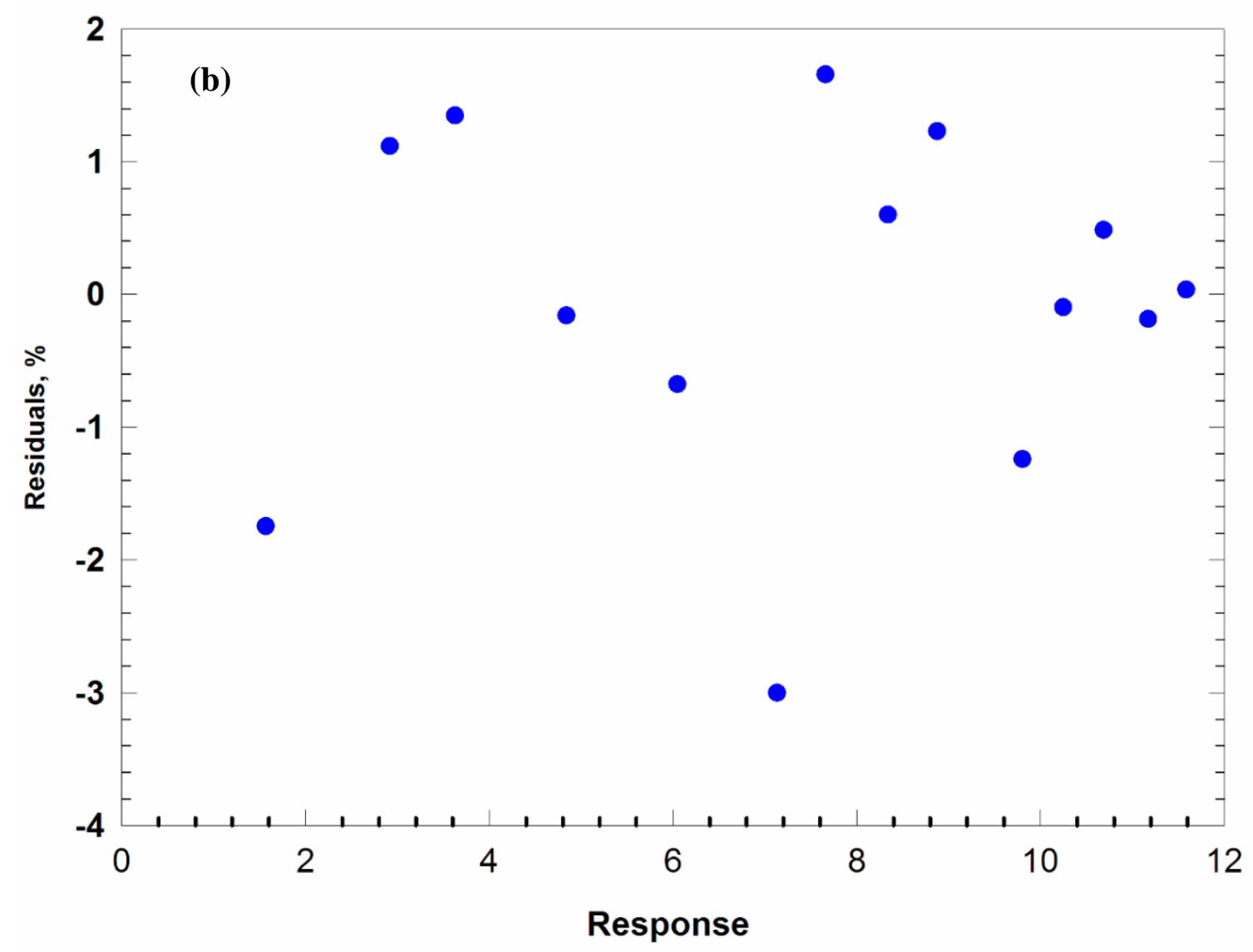

Fig. 4: (a) Calibration curve (reciprocal of response curve, Fig. 3) of DPD-PVA films for doses ranging from 0 to $269.1 \mathrm{kGy}$, as measured by the scanner and analyzed with the ImageJ software using the blue channel. Blue circles correspond to experimental results. The blue line indicates the nonlinear regression fit using a third degree polynomial, and the red curves show the $95 \%$ confidence intervals for individual values. (b) Residuals, \% against response obtained from the Table Curve.

\subsection{Raman spectroscopic analysis}

Fig. 5 shows the Raman spectra of neat DPD powder, unirradiated DPD-PVA films, and films irradiated at 20 and $100 \mathrm{kGy}$. Just like the Raman spectrum of the neat powder, the spectrum of an unirradiated film shows one line at $2258 \mathrm{~cm}^{-1}$ corresponding to the $v_{\mathrm{C} \equiv \mathrm{C}}$ of the diacetylene monomer. In addition, the absence of bands around 2073 and $1491 \mathrm{~cm}^{-1}$ confirms the absence of polymer. The spectra of the irradiated films show the presence of residual monomer (line at $2258 \mathrm{~cm}^{-1}$ ), along with bands at about $2086 \mathrm{~cm}^{-1}$ and $1496 \mathrm{~cm}^{-1}$ assigned to the $v_{\mathrm{C} \equiv \mathrm{C}}$ and $v_{\mathrm{C}=\mathrm{C}}$ vibrations of a PDA with an enyne structure. These bands are large, indicating the disordered state of the polymer chains. The peak positions are fairly close to those measured in the crystal (2073 and $1491 \mathrm{~cm}^{-1}$ ), suggestive of only a very slight effect of the embedding matrix on Raman frequencies. The Raman spectrum of the $100 \mathrm{kGy}$ irradiated film still revealed the presence of the monomer $\left(2258 \mathrm{~cm}^{-1}\right)$, agreeing with the fact that the response grows gradually with increasing doses beyond $100 \mathrm{kGy}$ (Fig. 3). However, the bands at 2082 and $1498 \mathrm{~cm}^{-1}$ have much higher intensities, in accord with the higher dose. Similarly to the 20 kGy irradiated sample, these bands are large. Additionally, no extra peaks were observed in the spectrum, consistent with the absence of degradation products. 

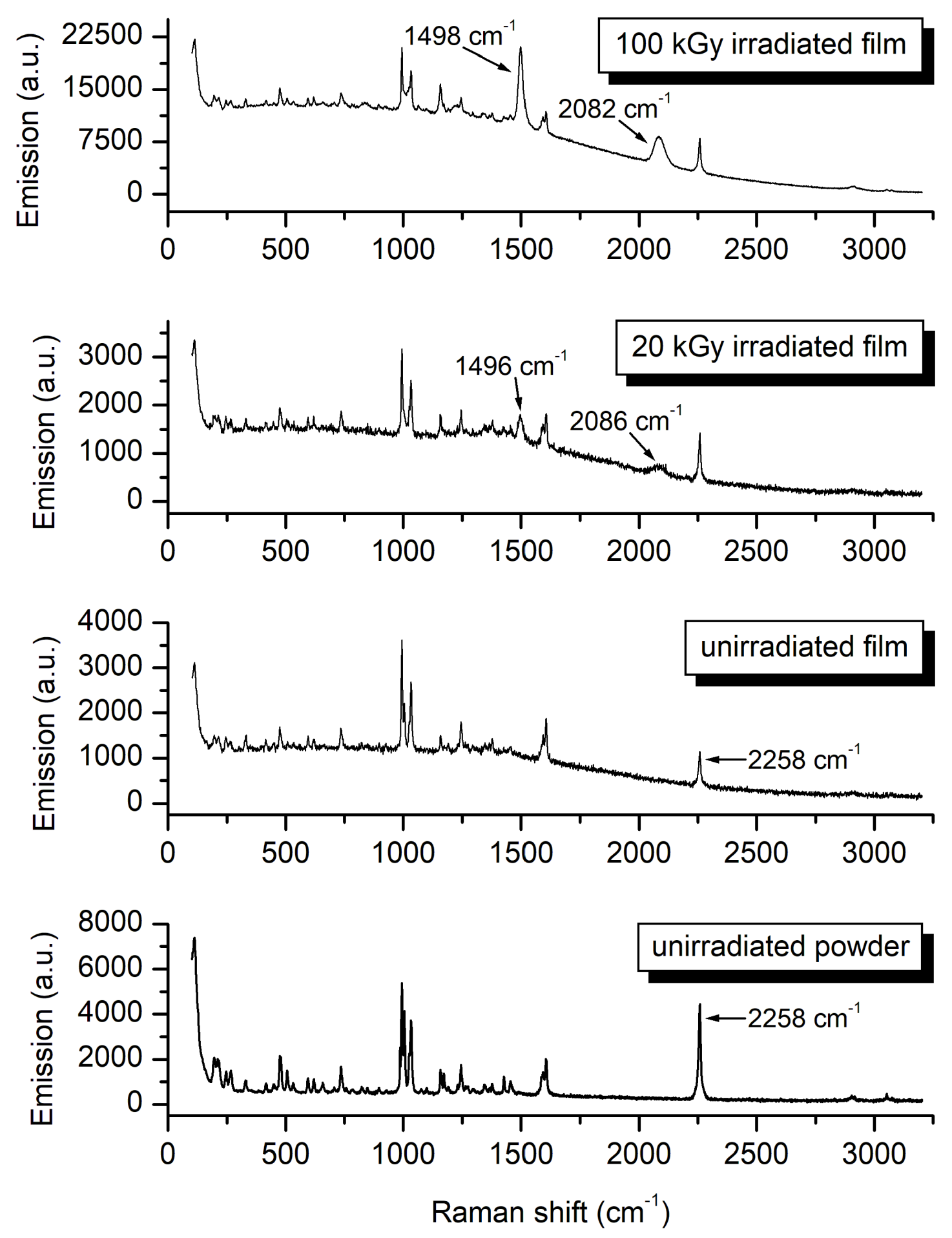

Fig. 5: Raman spectra of neat DPD powder, unirradiated DPD-PVA film, and films irradiated at 20 and 100 kGy. The excitation wavelength was $785 \mathrm{~nm}$. 
We have attempted to see if some quantitative information could be obtained from the Raman spectra shown in Fig. 5. Indeed, such information has been used in the past for ionizing radiation dosimetry using polyacrylamide gels (Baldock et al., 1998). In this work, Fourier transform Raman spectroscopy was employed to investigate the copolymerization of acrylamide with bis-acrylamide by monitoring the decrease in intensity of the vinyl $\delta_{\mathrm{CH} 2}$ vibrational bands of these monomers $\left(1285\right.$ and $\left.1256 \mathrm{~cm}^{-1}\right)$. In the present case, we have focused our attention on the $v_{\mathrm{C} \equiv \mathrm{C}}$ band of the monomer $\left(2258 \mathrm{~cm}^{-1}\right)$ and the $v_{\mathrm{C}=\mathrm{C}}$ and $v_{\mathrm{C} \equiv \mathrm{C}}$ bands of the polymer $\left(1498\right.$ and $\left.2082 \mathrm{~cm}^{-1}\right)$. To correct the intensities of these peaks for experimental errors caused by different signal-to-noise ratios between spectra, slight variations in the amounts of monomer in the films, etc., an internal reference was used, as suggested by Baldock (Baldock et al., 1998). Specifically, the intensities of these three bands have been normalized by the sum of the intensities of the two aromatic vibrations located at 1592 and $1604 \mathrm{~cm}^{-1}$. This being said, it is clear that our analysis suffers from a major drawback, which is the paucity of irradiation experiments (three), and, for each dose, only one film was analyzed. So, errors on the data points shown in the resulting plot (Fig. 6) are certainly high, and the following discussion should be considered with caution. In Fig.6, the 1498 and $2082 \mathrm{~cm}^{-1}$ curves both have some kind of polynomial shape, with fairly low intensities at 20 $\mathrm{kGy}$ and much higher intensities at $100 \mathrm{kGy}$. The $1498 \mathrm{~cm}^{-1}$ curve grows more rapidly than the $2082 \mathrm{~cm}^{-1} \mathrm{curve}$ Qualitatively, it looks as if the initial rate of polydiacetylene formation is high. Yet, great care must be exercised when studying diacetylene polymerization by Raman spectroscopy because the intensities of the $v_{\mathrm{C}=\mathrm{C}}$ and $v_{\mathrm{C} \equiv \mathrm{C}}$ bands are resonance-enhanced, so the results are biased. The two curves could be fitted with a second order polynomial of the type $\mathrm{y}=\mathrm{a}+\mathrm{bx}+\mathrm{cx}^{2}$, with, for the $1498 \mathrm{~cm}^{-1}$ band, $\mathrm{a}=-2.55 \times 10^{-15}, \mathrm{~b}=0.0387744$, and $\mathrm{c}=$ $7.81 \times 10^{-5}$, and, for the $2082 \mathrm{~cm}^{-1}$ line, $\mathrm{a}=-7.22 \times 10^{-16}, \mathrm{~b}=0.020743$, and $\mathrm{c}=1.05 \times 10^{-4}$. These equations provide an accurate description of the early steps of the polymerization reaction, but some additional terms will probably be necessary to model the full process, particularly to account for the fact that the lines will reach a plateau at very high absorded doses due to polymerization slowdown. Lastly, it must be emphasized that the knowledge of the intensity of a Raman band does not give any information about the amount of polymer present in the film, so comparison of the intensity of this band with external results obtained from gravimetric or UV-Vis spectrophotometric analyses is required if a kinetic study of diacetylene polymerization based on polymer formation is sought. Perhaps a more reliable way to grasp the rate of diacetylene polymerization is to look at the disappearance of the $v_{\mathrm{C}=\mathrm{C}}$ band of the monomer. Indeed, in this case, there is no problem due to resonance enhancement. Fig. 6 shows that the intensity change of the $2258 \mathrm{~cm}^{-1}$ band as a function of absorded dose is smooth: it decreases from about 1 at $0 \mathrm{kGy}$ to about 0.8 at $100 \mathrm{kGy}$ and looks more or less linear. This smooth decrease suggests that the polymerization reactivity of DPD is low, consistent with previous results obtained on single crystals (Al Choueiry et al., 2010; Deschamps et al., 2010). As for the previous lines, the intensity variation of the $2258 \mathrm{~cm}^{-1}$ band could be fitted with a second order polynomial with $\mathrm{a}=0.97, \mathrm{~b}=-2.70 \times 10^{-3}$, and $c=1.00 \times 10^{-5}$. Unfortunately, this equation has no solution, so it is not possible to determine the dose for which the amount of monomer is zero. 


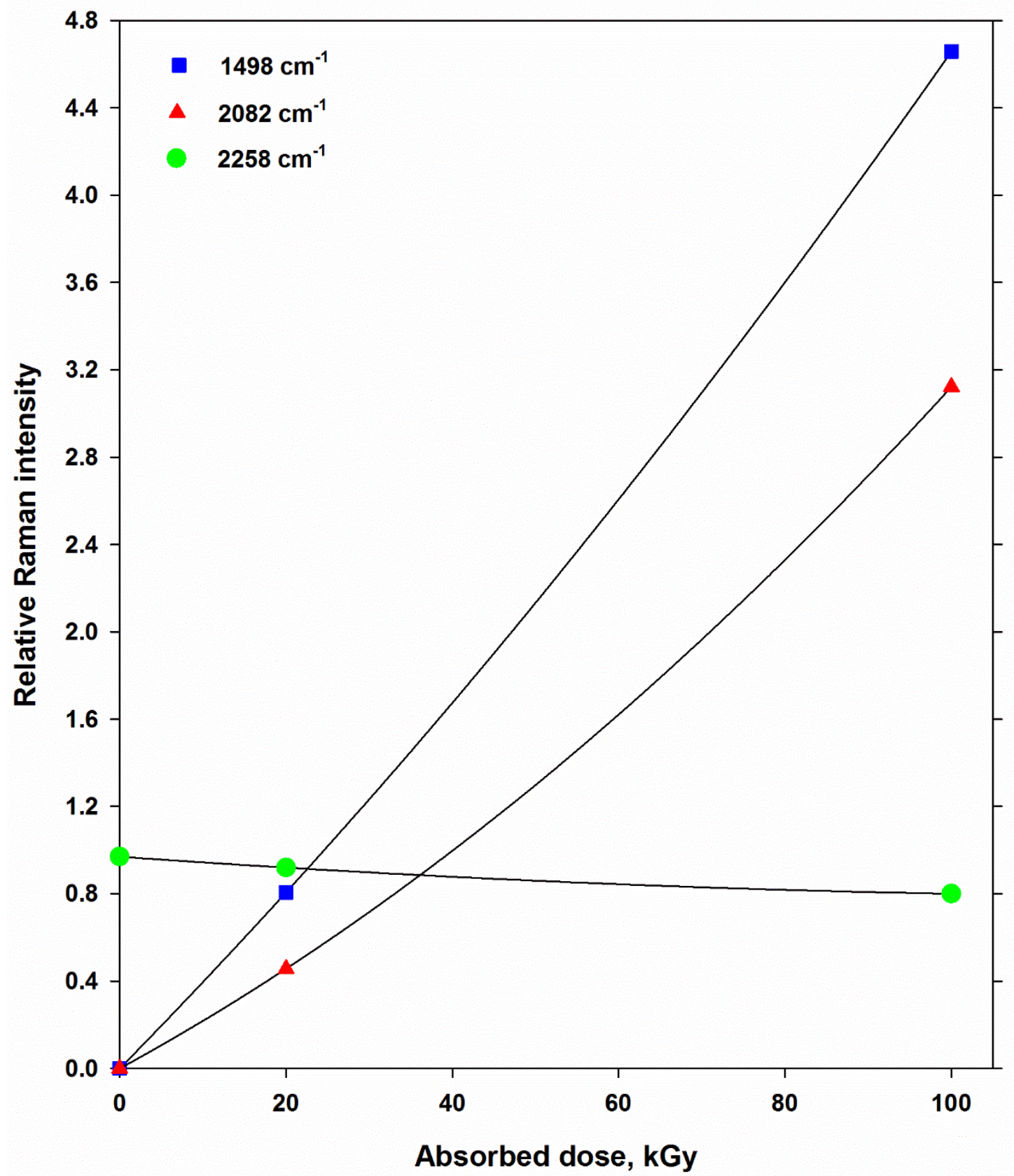

Fig. 6: Intensities of the 1498, 2082, and $2258 \mathrm{~cm}^{-1}$ Raman bands as a function of absorbed dose. The intensities of these three bands have been normalized by the sum of the intensities of the two aromatic vibrations located at 1592 and $1604 \mathrm{~cm}^{-1}$.

\subsection{Influence of humidity on the film response during irradiation}

The change of the DPD-PVA film response during irradiation is limited in the $0-75.3 \% \mathrm{RH}$ range; it amounts to about 4\% (Fig. 7). This small change may be due to the uncertainty or batch nonconformity (section 3.6). However, users should keep the films in tightly closed envelopes during irradiation, especially if they plan on using the films in an industrial facility where ${ }^{60} \mathrm{Co}$ pencils are stored in a pool of water. In addition, calibration of this film under actual irradiation conditions could greatly reduce any errors coming from the influence of RH during irradiation (ASTM International, 2015; Sharpe and Miller, 2009). These results are similar to those 
obtained previously for PCDA-PVB film dosimeters (Abdel-Fattah and Soliman, 2017): the response of PCDAPVB films varied by 4-6\% in the same RH range upon analysis at $670 \mathrm{~nm}$. In addition, PVA films containing the HDBU monomer showed a similar trend: the change in response with RH was within about 2\% (Soliman et al., 2014b).

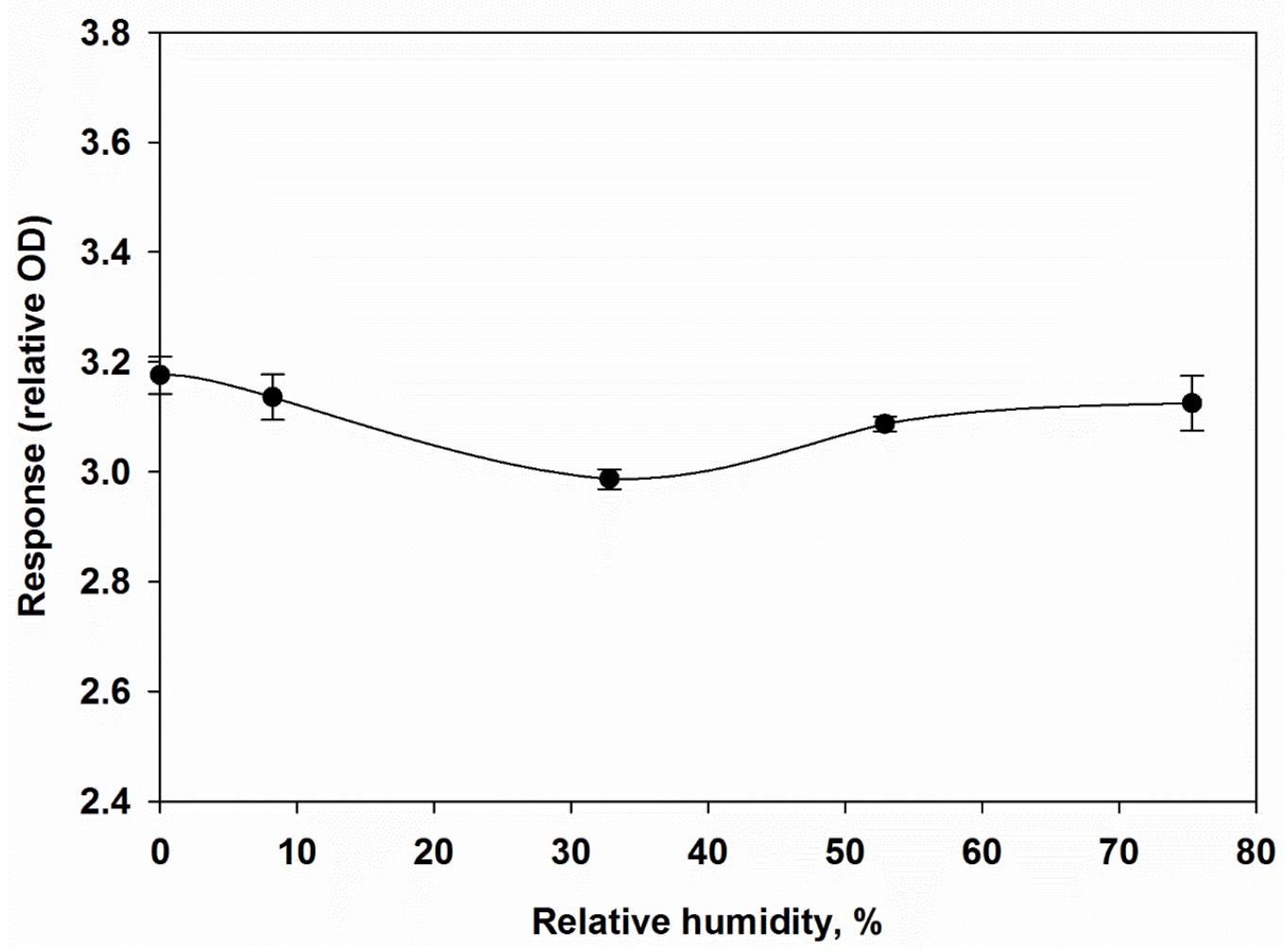

Fig. 7: Dependency of the dose response of DPD-PVA films on RH upon irradiation at a dose of $30 \mathrm{kGy}$, as analyzed by the scanner. The error bars represent standard deviations of measurements for four duplicate dosimeters.

\subsection{Post-irradiation stability}

The response of DPD-PVA films is quite stable in the dark and under standard white fluorescent laboratory lights (Fig. 8). The response increases by about $2 \%$ within $24 \mathrm{~h}$ after irradiation, then $3.1 \%$ after 13 days. After that, the response remains stable until the end of the storage period (50 days). This means that the dosimeter response is only slightly affected by light and the film can be utilized in routine analysis without any further protection from laboratory lights. This behavior is similar to that of HDBU-PVA films analyzed at $610 \mathrm{~nm}$ : the response in the dark or under light conditions increased by approximately $3 \%$ within $24 \mathrm{~h}$ after irradiation, and then remained stable until the end of the storage period (Soliman et al., 2014b). The response in the dark of better performing PCDA-PVB film types increases by $4 \%$ in the first 24 hours following irradiation, then grows more slowly with time (Abdel-Fattah and Soliman, 2017). However, the response of these films under light conditions increases by $8.7 \%$ in the first 24 hours following irradiation, then raises gradually with time. The present results indicate that the PCDA monomer is more sensitive to light than the DPD monomer, despite the fact that the storage conditions of DPD-PVA and PCDA-PVB were nearly the same. 


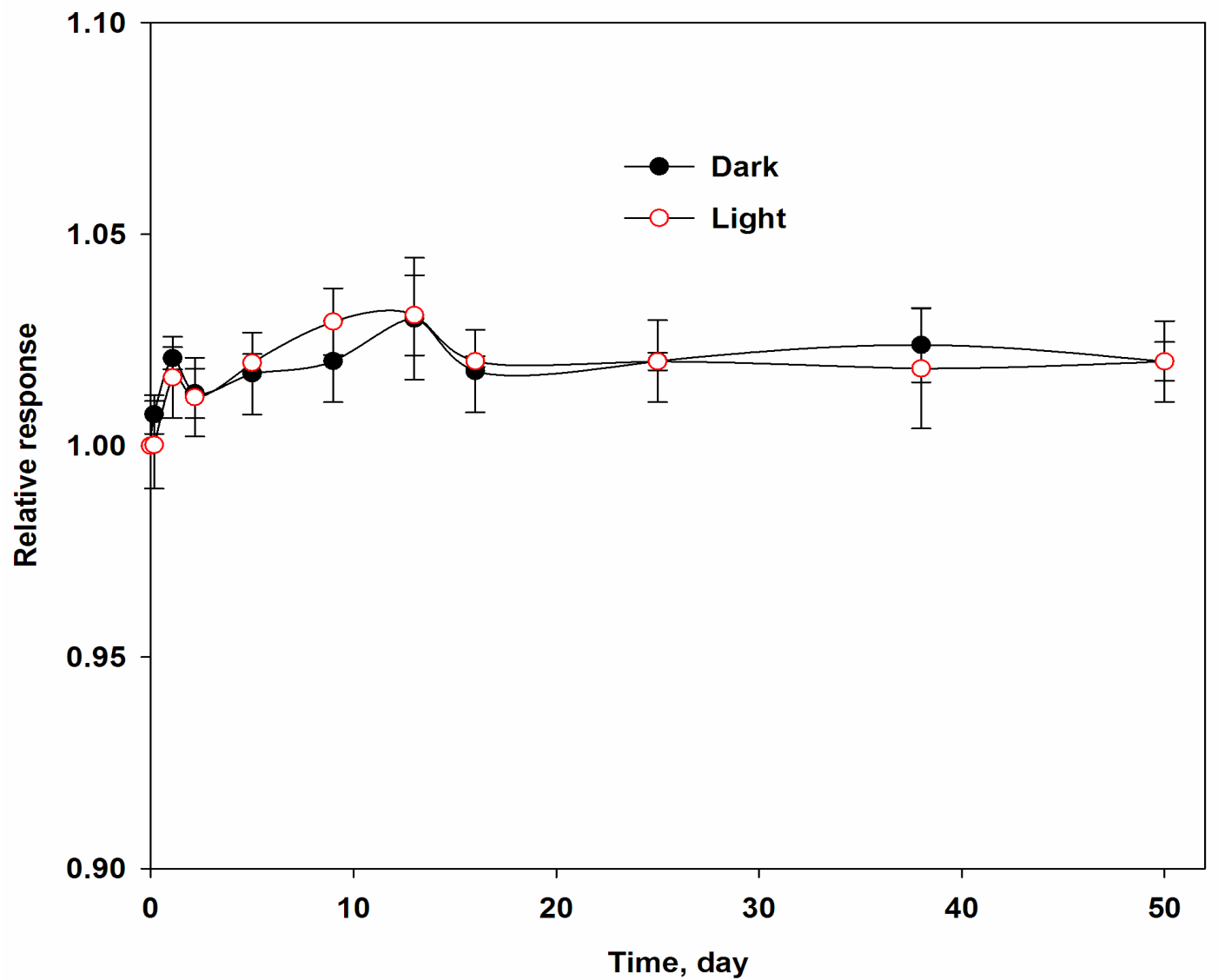

Fig. 8: Variation of the response of DPD-PVA film dosimeters as a function of storage time. The dosimeters were stored in the dark and under laboratory lights. The response is relative to the response value recorded immediately after irradiation (time zero).

\subsection{Uncertainty evaluation}

Table 2 summarizes the factors influencing dose measurements by the scanner for doses ranging from 2 to 269.1 kGy. The overall uncertainty of absorbed doses measured by DPD-PVA films was assessed on the basis of ISO/ASTM standards (ASTM International, 2015), guidelines (Sharpe and Miller, 2009; Taylor and Kuyatt, 2001), and literature reports (Abdel-Fattah et al., 2012; Soliman et al., 2018a). The expanded uncertainty on absorbed doses was estimated to be $4.46 \%$ ( $95 \%$ confidence interval). Thus, the monitoring of the conditions of irradiation during industrial use and the standardization of the conditions of calibration against those used in industrial irradiation may hold promise for the utilization of DPD-PVA films in radiation processing applications and allow for the reduction of the uncertainty value.

\subsection{Theoretical energy dependence}

Fig. 9 displays the $\left(\left(\mu_{\mathrm{en}} / \rho\right)_{\text {media }} /\left(\mu_{\mathrm{en}} / \rho\right)_{\text {water }}\right)$ values versus photon energy in the range of 0.01 to $20 \mathrm{MeV}$ for the DPD-PVA film dosimeters, tissues, and alanine samples. The theoretical energy response of the DPD-PVA film dosimeter is equivalent to the alanine energy response in the $0.15-20 \mathrm{MeV}$ photon energy range. In addition, it can be considered as a tissue equivalent in the $0.15-6 \mathrm{MeV}$ energy range, as the variation is less than $3 \%$ in this 
range. Last, the film may be regarded as a water-equivalent material in the $0.2-4 \mathrm{MeV}$ energy range, as a variation of less than $3 \%$ is observed.

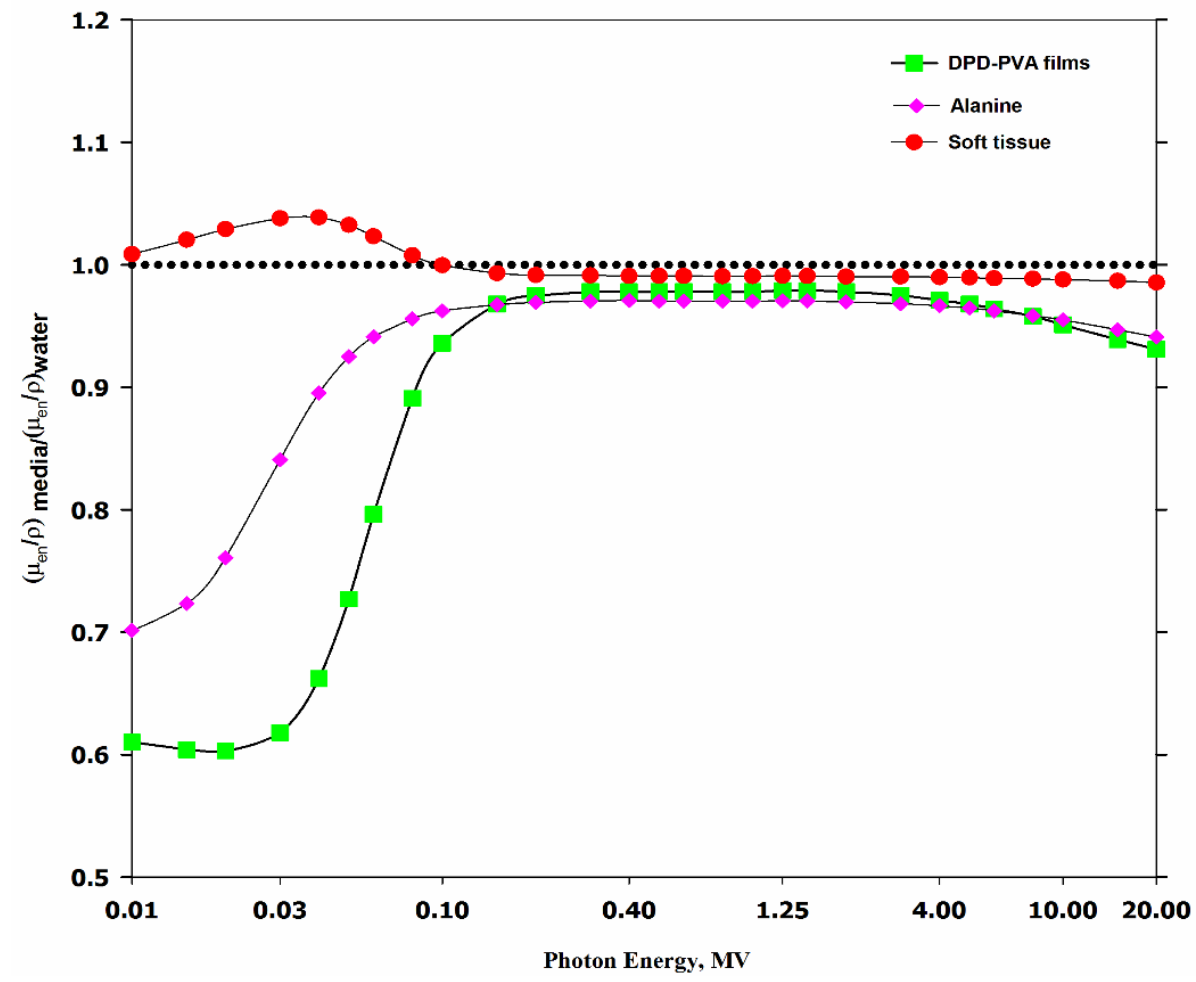

Fig. 9: Mass energy-absorption coefficient of media, $\left(\mu_{\mathrm{en}} / \rho\right)_{\text {media, }}$ of DPD-PVA films, soft tissue, and alanine dosimeter relative to $\left(\mu_{\mathrm{en}} / \rho\right)_{\text {water }}$, as a function of photon energy in the $0.01-20 \mathrm{MeV}$ range.

\section{Conclusion}

A radiochromic film dosimeter dubbed DPD-PVA was prepared by introducing a diacetylene monomer, DPD, a radiation-sensitive material, into a PVA matrix using an emulsion process. Table 3 summarizes some important features of the DPD-PVA films. This dosimeter can be analyzed with a spectrophotometer when the irradiation dose is in the range $0-90 \mathrm{kGy}$, but a high-resolution scanner in the reflective mode is more appropriate for dose monitoring in the 0-269.1 kGy range. Upon exposing this film to $\gamma$-rays, we noticed a color change from pale yellow to orange-yellow and then deep orange with increasing absorbed doses. Two bands are observed at 470 $\mathrm{nm}$ and $502 \mathrm{~nm}$ in the visible spectra of irradiated films, and these bands shifted to higher wavelengths with increasing absorbed doses. Raman analysis of irradiated films showed the presence of $v_{\mathrm{C} \equiv \mathrm{C}}$ and $v_{\mathrm{C}=\mathrm{C}}$ vibrations due to topochemical polymerization of DPD into a polydiacetylene with an enyne structure. The dosimeter response obtained from scanner analysis with the blue channel increased with increasing absorbed doses according to a third degree polynomial. Laboratory light had a limited impact on the dosimeter response after irradiation. The response in the dark or under light conditions became nearly stable after one day of storage. The change after that period was within $1.1 \%$. The film also showed little sensitivity to RH for RH values in the 0$75.3 \%$ range. Based on theoretical calculations, the energy response of DPD-PVA radiochromic films is equivalent to alanine standard dosimeters in the $0.15-20 \mathrm{MeV}$ photon energy range. The change in this range was about $4 \%$. The reported overall uncertainty on absorbed dose measurements with this film is $4.46 \%$.

In conclusion, the use of a high-resolution scanner in the reflective mode has proven quite useful in the analysis of DPD-PVA films. In addition, comparison of the dose results obtained with these films with those measured with FWT-60 dosimeters demonstrates relevance of using DPD-PVA films for routine dose control in industrial 
irradiation applications (food irradiation, medical device and healthcare product sterilization, and polymer modification technology).

Table 2: Uncertainty budget for doses measured with the DPD-PVA film dosimeter in the 2-269.1 kGy range, as measured by the Epson scanner in a reflective mode.

\begin{tabular}{lll}
\hline Source of uncertainty & $\begin{array}{l}\text { Type of } \\
\text { uncertainty }\end{array}$ & $\begin{array}{l}\text { Relative standard } \\
\text { uncertainty (\%) }\end{array}$ \\
\hline Calibration of ${ }^{60}$ Co research facility & B & $1.10^{\mathrm{a}}$ \\
Additional uncertainties in the ${ }^{60} \mathrm{Co} \mathrm{research} \mathrm{facility}$ & B & $0.44^{\mathrm{b}}$ \\
Sensitivity variation of the scanner ${ }^{\mathrm{c}}$ & A & 0.12 \\
Reproducibility of the scanner analyses ${ }^{\mathrm{d}}$ & A & 0.50 \\
Homogeneity of the dosimeters & A & 1.21 \\
Calibration curve fit & A & 1.36 \\
Combined standard uncertainty $\left(u_{c}\right)$ & & 2.23 \\
Expanded uncertainty $\left(2 u_{c}\right)$ & & 4.46 \\
\hline
\end{tabular}

${ }^{\text {a }}$ Obtained from the calibration certificate of NPL, UK.

${ }^{\mathrm{b}}$ Details are given in the literature (Mehta, 2006; Soliman et al., 2018a).

${ }^{\mathrm{c}}$ Calculated by measuring 15 times the OD of an irradiated DPD-PVA film, the film remaining in the sample position between measurements.

${ }^{d}$ Determined by measuring 15 times the OD of an irradiated film, the film being removed and reinserted between each analysis. 
Table 3: Characteristic features of DPD-PVA films.

\begin{tabular}{l|l}
\hline Item & Feature \\
\hline Color change & Pale yellow to yellow then orange with increasing absorbed doses \\
$\begin{array}{l}\text { Operating mode of dosimeter } \\
\text { Raman analysis of irradiated films }\end{array}$ & Two bands at 2082 and $1498 \mathrm{~cm}^{-1}$ assigned to $v_{\mathrm{C} \equiv \mathrm{C}}$ and $v_{\mathrm{C}=\mathrm{C}}$ \\
Threshold dose & $\sim 2 \mathrm{kGy}$ \\
Dynamic dose range & $2-269.1 \mathrm{kGy}$ \\
Linear dose range & Up to $30 \mathrm{kGy}$ \\
Radiation sensitivity & $0.075 \mathrm{kGy}$ for blue channel analysis \\
Stability in the dark or under light & Stable over the observation period (50 days) \\
Influence of RH & RH (0-75.3\%) has a limited impact on the response of the films \\
Overall uncertainty & $4.46 \%$ at $2 \sigma$ \\
Useful applications & Food irradiation, sterilization of medical devices and healthcare products, \\
& polymer modification, irradiation of gemstones like topaz \\
\hline
\end{tabular}

\section{Author statement}

Yasser S. Soliman prepared the radiochromic films, carried out most of experiments, discussed the results, performed the theoretical energy dependency calculations, and wrote the manuscript.

Atef A. Abdel-Fattah discussed the framework of this study with Yasser S. Soliman and shared his expertise in the preparation of radiochromic films.

Sylvain G. Dutremez performed the synthesis of the DPD monomer, carried the Raman analyses, and contributed to the writing and revision of the manuscript with Yasser S. Soliman.

All authors have read and approved the content of the manuscript.

\section{Declaration of competing interest}

The authors declare that they have no known competing financial interests or personal relationships that could have appeared to influence the work reported in this paper.

\section{References}

Abdel-Fattah, A.A., Abdel-Rehim, F., Soliman, Y.S., 2012. A new label dosimetry system based on pentacosadiynoic acid monomer for low dose applications. Radiat. Phys. Chem. 81, 70-76. https://doi.org/10.1016/j.radphyschem.2011.08.011

Abdel-Fattah, A.A., Beshir, W.B., Hegazy, E.S.A., Ezz El-Din, H., 2001. Photo-luminescence of Risø B3 and PVB films for application in radiation dosimetry. Radiat. Phys. Chem. 62, 423-428. https://doi.org/10.1016/S0969-806X(01)00223-7

Abdel-Fattah, A.A., Soliman, Y.S., 2017. Performance improvement of pentacosa-diynoic acid label dosimeter for radiation processing technology. Radiat. Phys. Chem. 141, 66-72. https://doi.org/10.1016/j.radphyschem.2017.06.006

Al Choueiry, A., Barisien, T., Holcman, J., Legrand, L., Schott, M., Weiser, G., Balog, M., Deschamps, J., Dutremez, S.G., Filhol, J.S., 2010. Twisted polydiacetylene quantum wire: Influence of conformation on 
excitons in polymeric quasi-one-dimensional systems. Phys. Rev. B - Condens. Matter Mater. Phys. 81, 125208/1-125208/11. https://doi.org/10.1103/PhysRevB.81.125208

Alqathami, M., Adamovics, J., Benning, R., Qiao, G., Geso, M., Blencowe, A., 2013. Evaluation of ultrasensitive leucomalachite dye derivatives for use in the PRESAGE® dosimeter. Radiat. Phys. Chem. 85, 204-209. https://doi.org/10.1016/j.radphyschem.2012.11.006

ASTM International, 2015. ISO / ASTM51707-15, Standard Guide for Estimation of Measurement Uncertainty in Dosimetry for Radiation Processing, in: Annual Book of ASTM Standards. SO/ASTM International, West Conshohocken, PA 19428-2959, USA.

Balakrishnan, S., Lee, S., Kim, J.M., 2010. Thermochromic reversibility of conjugated polymers derived from a diacetylenic lipid containing lithium salt. J. Mater. Chem. 20, 2302-2304. https://doi.org/10.1039/b923323g

Baldock, C., De Deene, Y., Doran, S., Ibbott, G., Jirasek, A., Lepage, M., McAuley, K.B., Oldham, M., Schreiner, L.J., 2010. Topical Review: Polymer gel dosimetry. Phys. Med. Biol. 55, R1-R63. https://doi.org/10.1088/0031-9155/55/5/R01

Baldock, C., Rintoul, L., Keevil, S.F., Pope, J.M., George, G.A., 1998. Fourier transform Raman spectroscopy of polyacrylamide gels (PAGs) for radiation dosimetry. Phys. Med. Biol. 43, 3617-3627. https://doi.org/10.1088/0031-9155/43/12/017

Basfar, A.A., Moftah, B., Lotfy, S., Al-Moussa, A.A., Soliman, Y.S., 2019. Evaluations of N-(Isobutoxymethyl) acrylamide gel dosimeter by NMR technique for radiotherapy and uncertainty in dose measurements. Appl. Radiat. Isot. 148. https://doi.org/10.1016/j.apradiso.2019.04.014

Basfar, A.A., Rabaeh, K.A., Mousa, A.A., 2012. Improved performance of nitro-blue tetrazolium polyvinyl butyral high dose film dosimeters. Radiat. Meas. 47, 1005-1008. https://doi.org/10.1016/j.radmeas.2012.07.008

Basfar, A.A., Rabaeh, K.A., Moussa, A.A., Msalam, R.I., 2011. Dosimetry characterization of nitro-blue tetrazolium polyvinyl butyral films for radiation processing. Radiat. Phys. Chem. 80, 763-766. https://doi.org/10.1016/j.radphyschem.2011.01.011

Baughman, R.H., 1972. Solid-state polymerization of diacetylenes. J. Appl. Phys. 43, $4362-4370$. https://doi.org/10.1063/1.1660929

Butson, E., Alnawaf, H., Yu, P.K.N., Butson, M., 2011. Scanner uniformity improvements for radiochromic film analysis with matt reflectance backing. Australas. Phys. Eng. Sci. Med. 34, 401-407. https://doi.org/10.1007/s13246-011-0086-0

Callens, M., Crijns, W., Simons, V., De Wolf, I., Depuydt, T., Maes, F., Haustermans, K., D’Hooge, J., D’Agostino, E., Wevers, M., Pfeiffer, H., Van Den Abeele, K., 2016. A spectroscopic study of the chromatic properties of GafChromic ${ }^{\mathrm{TM}}$ EBT3 films. Med. Phys. 43, 1156-1166. https://doi.org/10.1118/1.4941312

Chu, R.D.H., Van Dyk, G., Lewis, D.F., O’Hara, K.P.J., Buckland, B.W., Dinelle, F., 1990. GafchromicTM dosimetry media: A new high dose, thin film routine dosimeter and dose mapping tool. Int. J. Radiat. Appl. Instrumentation. Part 35, 767-773. https://doi.org/10.1016/1359-0197(90)90313-7

Deschamps, J., Balog, M., Boury, B., Yahia, M. Ben, Filhol, J.S., Van Der Lee, A., Al Choueiry, A., Barisien, T., Legrand, L., Schott, M., Dutremez, S.G., 2010. Tuning topochemical polymerization of diacetylenes: A 
joint synthetic, structural, photophysical, and theoretical study of a series ofanalogues of aknown reactive monomer, 1,6-bis(diphenylamino)-2,4-hexadiyne (THD). Chem. Mater. 22, 3961-3982. https://doi.org/10.1021/cm1008703

Devic, S., 2011. Radiochromic film dosimetry: Past, present, and future. Phys. Medica 27, $122-134$. https://doi.org/10.1016/j.ejmp.2010.10.001

Devic, S., Seuntjens, J., Hegyi, G., Podgorsak, E.B., Soares, C.G., Kirov, A.S., Ali, I., Williamson, J.F., Elizondo, A., 2004. Dosimetric properties of improved GafChromic films for seven different digitizers. Med. Phys. 31, 2392-2401. https://doi.org/10.1118/1.1776691

Devic, S., Seuntjens, J., Sham, E., Podgorsak, E.B., Schmidtlein, C.R., Kirov, A.S., Soares, C.G., 2005. Precise radiochromic film dosimetry using a flat-bed document scanner. Med. Phys. 32, 2245-2253. https://doi.org/10.1118/1.1929253

Eckhardt, H., Boudreaux, D.S., Chance, R.R., 1986. Effects of substituent-induced strain on the electronic structure of polydiacetylenes. J. Chem. Phys. 85, 4116-4119. https://doi.org/10.1063/1.450882

El Gohary, M.I., Soliman, Y.S., Amin, E.A., Gawad, M.H.A., Desouky, O.S., 2016. Effect of perchloric acid on the performance of the Fricke xylenol gel dosimeter. Appl. Radiat. Isot. 113, 66-69. https://doi.org/10.1016/j.apradiso.2016.04.024

Emi-Reynolds, G., Kovacs, A., Fletcher, J.J., 2007. Dosimetry characterization of tetrazolium violetpolyvinylalcohol films. Radiat. Phys. Chem. 76, 1519-1522. https://doi.org/10.1016/j.radphyschem.2007.02.064

Far West Technology Inc., 2020. FWT-60 Series Radiochromic Dosimeters, https://www.fwt.com/racm/fwt60ds.htm\#: :text=FWT\%2D60\%20SERIES\%20RADIACHROMIC\%20D OSIMETERS,in\%20relation\%20to\%20absorbed\%20dose.

Ferreira, B.C., Lopes, M.C., Capela, M., 2009. Evaluation of an Epson flatbed scanner to read Gafchromic EBT films for radiation dosimetry. Phys. Med. Biol. 54, 1073-1085. https://doi.org/10.1088/00319155/54/4/017

Greenspan, L., 1977. Humidity Fixed Points of Binary Saturated Aqueous Solutions. J Res Natl Bur Stand Sect A Phys Chem 81 A, 89-96. https://doi.org/10.6028/jres.081A.011

Hubbell, J.H., Seltzer, S.M., Hubblell, H.J., Seltzer, M.S., 1995. Tables of X-Ray Mass Attenuation Coefficients and Mass Energy-Absorption Coefficients $1 \mathrm{keV}$ to $20 \mathrm{MeV}$ for Elements $\mathrm{Z}=1$ to 92 and 48 Additional Substances of Dosimetric Interest, Nistir 5632. Nistir 5632, National Institute of Standards and Technolog, Gaithersburg, MD 20899.

Isa, N.M., Baharin, R., Majid, R.A., Rahman, W.A.W.A., 2017. Optical properties of conjugated polymer: review of its change mechanism for ionizing radiation sensor. Polym. Adv. Technol. 28, 1559-1571. https://doi.org/10.1002/pat.4067

ISO/ASTM, 2013. Standard practice for dosimetry in radiation processing, 52628:2013(E), in: Annual Book of ASTM Standards. https://doi.org/10.1520/E2628-19

Kawamura, I., Kawamoto, H., Fujimoto, Y., Koshimizu, M., Asai, K., 2020. Development of radiochromic dosimeters based on polyvinyl chloride films containing leuco crystal violet. Jpn. J. Appl. Phys. 59, 036003. https://doi.org/10.35848/1347-4065/abaa92

Klassen, N. V., Van Der Zwan, L., Cygler, J., 1997. GafChromic MD-55: Investigated as a precision dosimeter. 
Med. Phys. 24, 1924-1934. https://doi.org/10.1118/1.598106

Koeva, V.I., Csaszar, E.S., Senden, R.J., McAuley, K.B., Schreiner, L.J., 2008. Polymer gel dosimeters with increased solubility: A preliminary investigation of the NMR and optical dose-response using different crosslinkers and Co-solvents. Macromol. Symp. 261, 157-166. https://doi.org/10.1002/masy.200850121

Kovács, A., Baranyai, M., Wojnárovits, L., Slezsák, I., McLaughlin, W.L., Miller, A., Moussa, A., 2000. Dose determination with nitro blue tetrazolium containing radiochromic dye films by measuring absorbed and reflected light. Radiat. Phys. Chem. 57, 711-716. https://doi.org/10.1016/S0969-806X(99)00501-0

Kozicki, M., Sąsiadek, E., Kadłubowski, S., Dudek, M., Maras, P., Nosal, A., Gazicki-Lipman, M., 2018. Flat foils as UV and ionising radiation dosimeters. J. Photochem. Photobiol. A Chem. 351, 179-196. https://doi.org/10.1016/j.jphotochem.2017.10.028

Krishnan, D., Amal Raj, R.B., Gowd, E.B., 2019. Topochemical polymerization of hierarchically ordered diacetylene monomers within the block copolymer domains. Polym. Chem. 10, 3154-3162. https://doi.org/10.1039/c9py00156e

Lynch, B.D., Kozelka, J., Ranade, M.K., Li, J.G., Simon, W.E., Dempsey, J.F., 2006. Important considerations for radiochromic film dosimetry with flatbed CCD scanners and EBT GAFCHROMIC® film. Med. Phys. 33, 4551-4556. https://doi.org/10.1118/1.2370505

Mai, H.H., Solomon, H.M., Taguchi, M., Kojima, T., 2008. Polyvinyl butyral films containing leuco-malachite green as low-dose dosimeters. Radiat. Phys. Chem. 77, 457-462. https://doi.org/10.1016/j.radphyschem.2007.06.012

Matsuzawa, H., Okada, S., Sarkar, A., Matsuda, H., Nakanishi, H., 2001. Synthesis of polydiacetylenes from novel monomers having two diacetylene units linked by an arylene group. Polym. J. 33, 182-189. https://doi.org/10.1295/polymj.33.182

McLaughlin, William L., Al-Sheikhly, M., Lewis, D.F., Kovács, A., Wojnárovits, L., 1996. Radiochromic SolidState Polymerization Reaction. ACS Symp. Ser. 620, 151-166. https://doi.org/10.1021/bk-19960620.ch011

Mclaughlin, W.L., Desrosiers, M.F., 1995. Dosimetry systems for radiation processing. Radiat. Phys. Chem. 46, 1163-1174. https://doi.org/10.1016/0969-806X(95)00349-3

McLaughlin, W.L., Miller, A., Abdel-Rahim, F., Preisinger, T., 1985. Plastic film materials for dosimetry of very large absorbed doses. Radiat. Phys. Chem. 25, 729-748. https://doi.org/10.1016/0146-5724(85)90153-0

McLaughlin, W. L., Puhl, J.M., Al-Sheikhly, M., Christou, C.A., Miller, A., Kovács, A., Wojnarovits, L., Lewis, D.F., 1996. Novel radiochromic films for clinical dosimetry. Radiat. Prot. Dosimetry 66, $263-268$. https://doi.org/10.1093/oxfordjournals.rpd.a031731

Mehta, K., 2006. Radiation processing dosimetry, a practical manual. Gex Corporation.

Miller, A., Batsberg, W., Karman, W., 1988. A new radiochromic thin-film dosimeter system. Int. J. Radiat. Appl. Instrumentation. Part 31, 491-496. https://doi.org/10.1016/1359-0197(88)90216-0

Miller, A., Hargittai, P., Kovacs, A., 2000. A PC based thin film dosimeter system. Radiat. Phys. Chem. 57, 679-685. https://doi.org/10.1016/S0969-806X(99)00507-1

Miller, A., Mclaughlin, W.L., 1980. RISØ-M-2254 ON A RADIOCHROMIC DYE DOSE METER Arne Miller and William L. McLaughlin, RIS $\varnothing$ Report M-2254, RIS $\varnothing$ National Laboratory, DK 4000 Roskilde, Denmark. 
Ogawa, T., 1995. Diacetylenes in polymeric systems. Prog. Polym. Sci. 20, 943-985. https://doi.org/10.1016/0079-6700(95)00013-6

Paelinck, L., De Neve, W., De Wagter, C., 2007. Precautions and strategies in using a commercial flatbed scanner for radiochromic film dosimetry. Phys. Med. Biol. 52, 231-242. https://doi.org/10.1088/0031$9155 / 52 / 1 / 015$

Patel, G.N., 1981. Diacetylenes as radiation dosage indicators. Radiat. Phys. Chem. 18, 913-925. https://doi.org/10.1016/0146-5724(81)90282-X

Rink, A., Alex Vitkin, I., Jaffray, D.A., 2005a. Characterization and real-time optical measurements of the ionizing radiation dose response for a new radiochromic medium. Med. Phys. 32, 2510-2516. https://doi.org/10.1118/1.1951447

Rink, A., Vitkin, I.A., Jaffray, D.A., 2005b. Suitability of radiochromic medium for real-time optical measurements of ionizing radiation dose. Med. Phys. 32, 1140-1155. https://doi.org/10.1118/1.1877832

Samuel, I.D.W., Ledoux, I., Dhenaut, C., Zyss, J., Fox, H.H., Schrock, R.R., Silbey, R.J., 1994. Saturation of cubic optical nonlinearity in long-chain polyene oligomers. Science (80-. ). 265, 1070-1072. https://doi.org/10.1126/science.265.5175.1070

Sarkar, A., Kodali, N.B., Kamath, M.B., Bhagwat, L.P., Talwar, S.S., 1999. Solid state polymerization of diacetylenes with $\pi$-conjugating substituents for third-order nonlinear optical properties. J. Macromol. Sci. - Pure Appl. Chem. 36 A, 211-224. https://doi.org/10.1081/MA-100101526

Saylor, M.C., Tamargo, T.T., McLaughlin, W.L., Khan, H.M., Lewis, D.F., Schenfele, R.D., 1988. A thin film recording medium for use in food irradiation. Int. J. Radiat. Appl. Instrumentation. Part 31, 529-536. https://doi.org/10.1016/1359-0197(88)90222-6

Schneider, C.A., Rasband, W.S., Eliceiri, K.W., 2012. NIH Image to ImageJ: 25 years of image analysis. Nat. Methods 9, 671-675. https://doi.org/10.1038/nmeth.2089

Seltzer, S.M., 1993. Calculation of photon mass energy-transfer and mass energy-absorption coefficients. Radiat. Res. 136, 147-170. https://doi.org/10.2307/3578607

Sephton, J.P., Sharpe, P.H.G., Chu, R.D.H., O’Hara, K.P.J., Abdel-Rehim, F., Abdel Fattah, A., 2007. Dose mapping of a 60Co industrial irradiation plant using an electronic data recording system, static measurements and mathematical modelling. Radiat. Phys. Chem. 76, 1820-1825. https://doi.org/10.1016/j.radphyschem.2007.02.110

Sharpe, P., Miller, A., 2009. NPL REPORT CIRM 29. Guidelines for the Calibration of Routine Dosimetry Systems for use in Radiation Processing, Npl Report Cirm 29.

Soliman, Y.S., Abdel-Fattah, A.A., 2013. Leuco crystal violet/poly(vinyl butyral) thin film as a high-dose dosimeter. Radiat. Meas. 49. https://doi.org/10.1016/j.radmeas.2012.12.015

Soliman, Y.S., Abdel-Fattah, A.A., Alkhuraiji, T.S., 2018a. Radiochromic film containing poly(hexa-2,4diynylene adipate) as a radiation dosimeter. Appl. Radiat. Isot. 141, 80-87. https://doi.org/10.1016/j.apradiso.2018.08.016

Soliman, Y.S., Abdel-Fattah, A.A., Hamed, A.A., Bayomi, A.M.M., 2018b. A radiation-sensitive monomer of 2,4-hexadiyn-1,6-bis(p-toluene sulphonyl urethane) in PVA as a radiochromic film dosimeter. Radiat. Phys. Chem. 144, 56-62. https://doi.org/10.1016/j.radphyschem.2017.11.012

Soliman, Y.S., Basfar, A.A., Msalam, R.I., 2014a. A radiochromic film based on leucomalachite green for high- 
dose dosimetry applications. Radiat. Meas. 62, 45-51. https://doi.org/10.1016/j.radmeas.2014.01.004

Soliman, Y.S., Bayomi, A.M.M., Abdel-Fattah, A.A., Abdel-Khalek, A.A., 2014b. Radiochromic label dosimeter based on a synthesized monomer of 2,4-hexadiyn-1,6-bis(n-butyl urethane). Sensors Actuators, B Chem. 200, 109-116. https://doi.org/10.1016/j.snb.2014.04.045

Soliman, Y.S., Beshir, W.B., Abdel-Fattah, A.A., 2013a. Ultraviolet spectral analysis of polyvinyl (Butyral) Film Incorporating 10,12-Pentacosadiynoic acid monomer for application in radiation-processing dosimetry. Int. J. Polym. Mater. Polym. Biomater. 62, 203-208. https://doi.org/10.1080/00914037.2011.641637

Soliman, Y.S., Beshir, W.B., Abdel-Fattah, A.A., Abdel-Rehim, F., 2013b. Dosimetric studies for gamma radiation validation of medical devices. Appl. Radiat. Isot. 71, 21-28. https://doi.org/10.1016/j.apradiso.2012.09.016

Soliman, Y.S., Beshir, W.B., Abdel-Fattah, A.A., Fahim, R.A., El-Anadouli, B.E., 2016. Radiation-induced coloration of xylenol blue/film containing hexachloroethane for food irradiation applications. J. Radioanal. Nucl. Chem. 310, 117-124. https://doi.org/10.1007/s10967-016-4747-z

Soliman, Y.S., El Gohary, M.I., Abdel Gawad, M.H., Amin, E.A., Desouky, O.S., 2017. Fricke gel dosimeter as a tool in quality assurance of the radiotherapy treatment plans. Appl. Radiat. Isot. 120, 126-132. https://doi.org/10.1016/j.apradiso.2016.12.004

Sun, P., Fu, Y.C., Hu, J., Hao, N., Huang, W., Jiang, B., 2016. Development and dosimetric evaluation of radiochromic PCDA vesicle gel dosimeters. Radiat. Meas. 85, 116-125. https://doi.org/10.1016/j.radmeas.2015.12.037

Taylor, B.N., Kuyatt, C.E., 2001. Guidelines for Evaluating and Expressing the Uncertainty of NIST Measurement Results: Appendix D1. Terminology, National Institute for Standards and Technology, Gaithersburg, MD.

Vaiano, P., Consales, M., Casolaro, P., Campajola, L., Fienga, F., Di Capua, F., Breglio, G., Buontempo, S., Cutolo, A., Cusano, A., 2019. A novel method for EBT3 Gafchromic films read-out at high dose levels. Phys. Medica 61, 77-84. https://doi.org/10.1016/j.ejmp.2019.04.013

Van Battum, L.J., Hoffmans, D., Piersma, H., Heukelom, S., 2008. Accurate dosimetry with GafChromic ${ }^{\mathrm{TM}}$ EBT film of a $6 \mathrm{MV}$ photon beam in water: What level is achievable? Med. Phys. 35, 704-716. https://doi.org/10.1118/1.2828196

Vandana, S., Shaiju, V.S., Sharma, S.D., Mhatre, S., Shinde, S., Chourasiya, G., Mayya, Y.S., 2011. Dosimetry of gamma chamber blood irradiator using Gafchromic EBT film. Appl. Radiat. Isot. 69, 130-135. https://doi.org/10.1016/j.apradiso.2010.08.018

Watanabe, Y., Patel, G.N., Patel, P., 2006. Evaluation of a new self-developing instant film for imaging and dosimetry. Radiat. Prot. Dosimetry 120, 121-124. https://doi.org/10.1093/rpd/nci551

Wegner, G., 1972. Topochemical Polymerization of Monomers with Conjugated Triple Bonds *). Die Makromol. Chemie 154, 35-48. https://doi.org/10.1002/macp.1972.021540103

Wegner, G., 1971. Topochemical reactions of monomers with conjugated triple-bonds. IV. Polymerization of bis-(p-toluene sulfonate) of 2.4-hexadiin-1.6-diol. Die Makromol. Chemie 145, 85-94. https://doi.org/10.1002/macp.1971.021450107

Weston, M., Tjandra, A.D., Chandrawati, R., 2020. Tuning chromatic response, sensitivity, and specificity of polydiacetylene-based sensors. Polym. Chem. 11, 166-183. https://doi.org/10.1039/c9py00949c 
Wexler, A., Hasegawa, S., 1954. Relative humidity-temperature relationships of some saturated salt solutions in the temperature range 0 degree to 50 degrees C. J. Res. Natl. Bur. Stand. (1934). 53, 19. https://doi.org/10.6028/jres.053.003

Williams, M., Metcalfe, P., 2011. Radiochromic film dosimetry and its applications in radiotherapy, in: AIP Conference Proceedings. American Institute of Physics 978-0-7354-0901-9/\$30.00, pp. 75-99. https://doi.org/10.1063/1.3576160 